\title{
«[e]scrofulas, que dizen porcas»: notas críticas y léxicas sobre un pasaje del Tratado de Alveitaria ${ }^{*}$
}

GERARDO PÉREZ BARCALA

Universidade de Santiago de Compostela

A Mercedes

\section{EL DE MEDICINA EQUORUM DE GIORDANO RUFFO Y SU CONTEXTO ROMÁNICO: LA TRADUCCIÓN GALLEGA}

En el segundo cuarto del siglo XX, Juan Domínguez Fontela puso a disposición de la comunidad científica, por vez primera, una obra que, conocida desde entonces como Tratado de Albeitaria (cf. Domínguez Fontela 1938-1939, 1939-1940, 1940), ocupa un lugar singular en el conjunto de la prosa medieval gallega, al ser el único texto de carácter técnico existente para una tradición constituida fundamentalmente por crónicas, obras jurídicas y textos de materia clásica y artúrica ${ }^{1}$. A esta edición del texto, que el clérigo e historiador natural de A Guarda (Pontevedra) realizó a partir de la consulta directa del manuscrito que lo transmitía y del que entonces era propietario, siguió otra de la que se encargó José Luis Pensado Tomé: aunque el trabajo vio la luz después de su muerte, ocurrida en el año 2000, las inquietudes del estudioso por la obra se iniciaron en la década de los 70 del siglo XX y, afanado, como era natural por parte de tan reputado conocedor de la lexicografía, en ofrecer un glosario para tan singular y difícil texto (dado su carácter científico), presentó una transcripción del mismo, que elaboró a partir de unas fotocopias del manuscrito que, estando en aquel momento - los años 70 de la pasada centuria - en manos de Manuel Valcarce Reboreda, Pensado Tomé tuvo a bien incorporar en su estudio ( $c f$. Pensado Tomé 2004). En el proceso de revisión del trabajo del insigne filólogo, nos percatamos de la urgencia de un establecimiento textual del Tratado que se plasmó en una primera edición de carácter provisional, incorporada como apéndice a la de Pensado Tomé ( $c f$. Pérez Barcala 2004) y sucedida por otra que, por mucho que no resuelva todos los loci critici, se pretende más definitiva ( $c f$. Pérez Barcala 2013) ${ }^{2}$.

\footnotetext{
* Este trabajo es resultado de las investigaciones realizadas en el proyecto Textos para o corpus galego-portugués medieval: o Livro d'Alveitaria portugués e o Tratado de Alveitaria galego, subvencionado por la Xunta de Galicia en el marco del «Programa de apoio á etapa posdoutoral do Plan Galego de investigación, innovación e crecemento 2011-2015 (Plan I2C)». Vaya desde aquí mi sincero agradecimiento al profesor Enrique Montero Cartelle, pues su amabilidad y disponibilidad permitieron el acceso a algunos textos médicos medievales cuya consulta habría sido difícil, sino imposible, de otros modos

${ }^{1}$ Para una visión de conjunto de la prosa medieval gallega y la singular posición que en ella ocupa esta obra, vid., entre otros, Lorenzo (1998, 2000), López Martínez-Morás (2007).

${ }^{2}$ Salvo indicación contraria, las citas del texto gallego se darán siempre a partir de esta edición, señalando la(s) línea(s) y el parágrafo en que se localiza el pasaje que en cada caso se reproduzca.
} 
Nuestras propuestas no se limitan a la reproducción paleográfica, en tanto que, además de regularizar la diversidad gráfica que el texto presenta en el testimonio que lo transmite, procuran corregir algunos de los errores que este ofrece, pues lo conservado «é uma cópia, com erros, dum original perdido, provavelmente do século XIV» (Lorenzo 1993: 635).

Quizá la circunstancia de haberse difundido como Tratado de Albeitaria ${ }^{3}$ enmascaró la auténtica naturaleza de la obra, pues, aunque desde el trabajo de Domínguez Fontela se sabe que tras ese título se oculta la traducción gallega del manual latino de veterinaria conocido como De medicina equorum desde la pionera edición de Molin (1818) ${ }^{4}$, hasta fechas relativamente recientes el texto gallego había sido ignorado en el estudio de la difusión del referido manual y no se había incluido entre los testimonios que lo hicieron llegar. Sin embargo, un folio incorporado en la fase de encuadernación del manuscrito se muestra elocuente al ofrecer para el Tratado un título, «De Medicaminibus Equorum - De Morbis equorum - ad Federicum II Imperatorem - por Jordan Rubio de Calabria» (fol. 1r), que no ofrece dudas al respecto de la integración de la obra como una tesela más del mosaico que conforma la rica tradición del De medicina equorum. Ese códice, de inicios del siglo $\mathrm{XV}$, tras haber pasado por vicisitudes como las arriba comentadas, se conserva actualmente en la Biblioteca Nacional de España con la signatura ms. 23076 y, además de la versión gallega del manual de veterinaria, contiene diversos documentos fechados entre 1409 y 1420, todos ellos copiados, como el mismo Tratado, por el notario Álvaro Eanes da Seira, natural de la villa pontevedresa de Baiona ${ }^{5}$.

El De medicina equorum fue escrito presumiblemente en latín poco después de la muerte de Federico II (1250) por el noble de origen calabrés Giordano Ruffo, cuyo fallecimiento, pese a lo impreciso de su biografía, suele situarse en $1256^{6}$. Este, según declara en la misma obra, había ejercido el cargo de miles in marestalla en la corte del emperador siciliano, a quien con ella pretende honrar ${ }^{7}$. El carácter práctico de la obra, resultado de la experiencia que el autor había adquirido en el ejercicio de su profesión, fue deter-

${ }^{3} \mathrm{O}$ más bien Tratado de Alveitaria, si se tiene en cuenta que, como derivados del nombre árabe beitar, en el manuscrito aparecen los sustantivos alveitaria — «foi esprovado na alveitaria dos cavalos» (ls. 1750-1751, explicit) - y alveiter — «por desensinança do alveiter» (1. 1672, § 60.1), «por negregencia do alveiter» $(1.1684, \S 61.1)$ - para referirse respectivamente a la disciplina veterinaria y a quienes la practicaban.

${ }^{4}$ La crítica suele referirse a la obra como Hippiatria o De medicina equorum, títulos «la cui fortuna —en palabras de Montinaro (2009: 489, n. 85) - probabilmente si deve alla circonstanza che esse siano utilizzate in Molin 1818». En relación con este particular, comenta Gaulin (1994: 426, n. 10) que "si rilevano tra altri titoli: Mariscalcia equorum (Parigi, Bibl. Naz., Lat. 2477), Liber de curis equorum (Città del Vaticano, Bibl. Vat., Vat. Lat. 5331), Cyrurgia equorum (Bologna, Bibl. Univ., 2764) ma mai — che io sappia—il titolo De medicina equorum pur riportato da Molin».

${ }^{5}$ El título, tomado del referido folio de incorporación tardía, fue utilizado también para dar nombre a todo el manuscrito en la ficha que lo describe en la Biblioteca Nacional — «De medicaminibus equorum, de morbis equorum: ad Federicum II Imperatorem / por Jordam Rubio de Calabria»-, por considerarse que el tratado de veterinaria, aunque es precedido y seguido por los documentos notariales, es el texto principal del códice, lo que también fue determinante en la foliación del mismo. Vid. Pérez Barcala (2013: 62-66).

${ }^{6}$ Aunque esta es la opinión comúnmente aceptada, sobre la lengua (el latín) y la fecha (entre 1250 y 1256) en la que fue escrito el texto original hay opiniones diferentes. Para una revisión de estas cuestiones, vid. Montinaro (2009: 493-494; 2010: 33-35; 2015: 15-17).

${ }^{7}$ Sobre la función de miles in marestalla y otros detalles del impreciso perfil biográfico de Ruffo, vid. Montinaro (2009: 489-492; 2010: 30-33; 2015: 9-14). 
minante en el éxito y en la difusión de la misma: dado que el animal en el que Ruffo centra su atención es el caballo, concretamente el que era signo de distinción de las clases elevadas ${ }^{8}$, y dado que el noble debía tener conocimientos de veterinaria para saber cuidar al animal que lo distinguía ${ }^{9}$, no sorprende que este texto fuese ampliamente difundido en latín y traducido ya desde fechas tempranas a distintas lenguas románicas: dejando de lado algunos códices donde la identificación del tratado de Ruffo no es unívoca o segura, Montinaro (2015) registra un total de 173 manuscritos, de los que 57 transmiten la obra en latín y los restantes ofrecen versiones a diferentes romances: además de al gallego (1), el manual fue traducido al italiano (94) —en distintas variedades lingüísticas, entre las que se encuentra el siciliano, lengua en la que el texto se conserva en 4 testimonios y en la que, en opinión de un cierto sector de la crítica, habría sido escrito el original ${ }^{10}$ - , al francés (8), al occitano (1), al catalán (2), e incluso al alemán (6) y al hebreo (1).

De la amplia difusión del De medicina equorum, que se completa con 3 códices bilingües que conservan la obra en latín y también en alguna lengua romance ( 2 en francés y 1 en siciliano) y con 16 impresos que la transmiten exclusivamente en italiano, se tiene, no obstante, un conocimiento tan limitado que el establecimiento del stemma del tratado y la reconstrucción de su forma original no parecen por el momento tareas de fácil ejecución, toda vez que las versiones editadas, salvo las transmitidas por un único manuscrito (como es el caso de la occitana o la gallega), adolecen de haber visto establecido su texto a partir de uno solo de los testimonios que las hicieron llegar. El texto latino, transmitido por un número de ejemplares que, como se ha dicho, se aproxima a 60 , es conocido a partir de la citada edición de Molin (1818), que, con casi dos siglos a sus espaldas, toma como base un único testimonio, el ms. Lat. Cl. VII 24 (=3677) de la Biblioteca Nazionale Marciana de Venezia, del siglo XIII ${ }^{11}$, cuyo texto podría aproximarse bastante al que debió de ser el original de Ruffo y desempeñar, por lo tanto, la función de textus receptus del De medicina equorum $^{12}$. Otro tanto puede decirse de la vasta difusión de la que fue objeto la obra en alguna variedad lingüística italiana: por un lado, un manuscrito del siglo XIV que pertenece a una colección privada (Lanza di Trabia) transmite una versión siciliana que

${ }^{8}$ Como bien explica Gaulin (1994: 430), «questo libro tratta dunque del cavallo nobile, [...]. Questa nobiltà del cavallo [...] è quella di coloro che lo utilizzano. L'animale che Ruffo sa allevare e curare è un mezzo di distinzione sociale».

${ }^{9}$ Elocuentes son al respecto, por ejemplo, las palabras de Alfonso X: en la ley 10 del título XXI de la Partida Segunda el monarca expone que «los cavalleros deven seer sabidores de conoscer las bestias» y dispone que es de su competencia «saberlos [scil. a los caballos] mantener en sus bondades», «sy alguna mala costunbre oviesen tollerlos della» y «guarescerlos de las enfermedades que oviesen» (Juárez Blanquer y Rubio Flores 1991: 182-183).

${ }^{10}$ No obstante, la hipótesis de una redacción en siciliano del texto original de Ruffo parece poco probable ( $c f$. n. 6 para la bibliografía sobre el asunto).

${ }^{11}$ Hunt (2011: 35, n. 1) y Montinaro (2015: 34) constatan que el texto latino de Ruffo incluido en el ms. Latin 5503 de la Bibliothèque nationale de France ha sido editado en una tesis doctoral a la que no se ha podido tener acceso ( $c f$. Prévot 1989).

${ }^{12}$ No obstante, la presencia en el texto de este manuscrito de «una appendice finale non contemplata nel prologo e denominata Regulae cognitionum omnium equorum, breve trattato di fisiognomica applicata al cavallo articolato in due capitoli» (Montinaro 2010: 35), podría ser indicio de que esa sección no formaba parte del original de la obra. Para este apartado final en la tradición romance de la obra, vid. Montinaro (2010: 45-46; 2015: 17-18, 38, 39, 46). 
dio a conocer De Gregorio (1905) ${ }^{13}$; por otro lado, en un códice misceláneo de procedencia pisana de finales del siglo XIII, el ms. 78 C 15 del Kupferstichkabinett de Berlin, se reproduce una adaptación italiana cuyo texto fue fijado por Olrog Hedvall $(1995)^{14}$. De la transmisión de Ruffo en lengua francesa se conoce el texto enviado por el ms. français 25341 de la Bibliothèque Nationale de France, del siglo XIII, de cuya edición se hizo cargo Prévot (1991): a pesar de considerar como codex optimus el citado ejemplar parisino (identificado como $M$ ), la estudiosa registra las variantes de otros testimonios, entre los que se encuentran el ms. Reg. lat. 1177 de la Biblioteca Apostolica Vaticana $(N)$ - que previamente había editado Klein (1969) y que «est probablement une copie d'après un texte français et non une traduction directe du latin» (Prévot 1991: 17) - , el ms. 991 de la Bibliothèque Municipale de Reims $(R)$ — que «est la traduction du manuscrit latin de la bibliothèque du Vatican lat. 5331» (Prévot 1991: 17)—, el ms. n.a.l. 1553 de la Bibliothèque Nationale de France $(S)$ - uno de los tres códices bilingües que incluyen el tratado-y el ms. 546/5 de la Wellcome Library de Londres $(W)$ - que, al ofrecer una versión bastante deturpada del tratado, es tomado en consideración por la estudiosa de forma puntual ${ }^{15}$ - . El conjunto de testimonios del De medicina equorum cuyo texto ha sido establecido se completa con el ms. 9 de la Bibliothèque Municipale de Fréjus, del siglo XV, que contiene una versión occitana de la obra cuya edición fue presentada como tesis doctoral por Arquint (2006-2007). En suma, el puñado de ejemplares editados de la tradición latina y romance del manual de Ruffo al que se ha tenido acceso puede establecerse como sigue:

\begin{tabular}{|l|l|l|}
\hline VERSIÓN & \multicolumn{1}{|c|}{ MANUSCRITO } & \multicolumn{1}{|c|}{$\begin{array}{c}\text { EDICIÓN DE } \\
\text { REFERENCIA }\end{array}$} \\
\hline Latina & $\begin{array}{l}\text { Venezia, Biblioteca Nazionale Marciana, Lat. Cl. VII } \\
24 \text { (=3677), s. XIII, fols. 55r-69v }\end{array}$ & Molin (1818) \\
\hline Siciliana & $\begin{array}{l}\text { Roma (?), colección privada (Lanza di Trabia), s. XIV } \\
\text { (1368), fols. 8r-41v }\end{array}$ & De Gregorio (1905) \\
\hline
\end{tabular}

${ }^{13}$ En los últimos años varios trabajos de investigación, por el momento inéditos, se han interesado por otros testimonios que contienen versiones de Ruffo al siciliano. Por un lado, el ms. It. Cl. III 27 (= 5008 ) de la Biblioteca Nazionale Marciana de Venezia incluye una traducción con amplificaciones de cuya edición se ocuparon Di Costa (2000-2001) y Stivala (2013-2014). Por otro lado, el ms. 2934 de la Biblioteca Riccardiana de Firenze contiene, dos tratados (el primero entre los fols. 3r-35r, el segundo entre los fols. 36v-58r), que, incompletos, solo pueden relacionarse parcialmente con el De medicina equorum en tanto que, si bien el calabrés es traducido en algunos capítulos, en otros se manejan fuentes distintas (Bartolomeo da Messina y Lorenzo Rusio), como ha estudiado Fichera (2013): este último autor se ha encargado, asimismo, de la edición de los dos manuales del códice florentino en una tesis doctoral ( $c f$. Fichera 2014-2015) que sustituye a la precedente de La Rosa, que se había interesado por el segundo tratado de dicho ejemplar en su tesi di laurea ( $c f$. La Rosa 1999-2000). Para una panorámica de los tratados medievales de veterinaria en siciliano, vid. Pagano (en prensa).

${ }^{14}$ El texto había sido transcrito antes por Hiepe (1990). El códice Vat. lat. 1001 de la Biblioteca Apostolica Vaticana (siglo XV) conserva la traducción italiana del De medicina equorum redactada por Cola de Jennaro cuya edición fue objeto de dos trabajos de investigación inéditos que no ha sido posible consultar (cf. Urso 1990-1991; Montinaro 2008-2009).

${ }^{15}$ Explica Prévot (1991: 20) que «si ce texte a bien le traité de Rufus comme point de départ, il a été mal traduit, mal copié, modifié». Para la versión francesa de este ejemplar, en la que faltan varios capítulos y otros fueron abreviados, vid. Hunt (2011: 245-271). 


\begin{tabular}{|l|l|l|}
\hline Italiana & $\begin{array}{l}\text { Berlin, Kupferstichkabinett, 78 C 15, s. XIII, fols. 1r- } \\
48 \mathrm{v}\end{array}$ & Olrog Hedvall (1995) \\
\hline Francesa & $\begin{array}{l}\text { Paris, Bibliothèque Nationale de France, français } \\
25341, \text { s. XIII, fols. 1r-30v }\end{array}$ & Prévot (1991) \\
\hline Occitana & $\begin{array}{l}\text { Fréjus, Bibliothèque Municipale, ms. 9, s. XV, fols. } \\
\text { 1r-71r }\end{array}$ & Arquint (2006-2007) \\
\hline
\end{tabular}

La comparación de los ejemplares presentados (y de los otros que no hemos podido consultar) no solo es de utilidad para situar cualquiera de ellos en el contexto de la difusión del De medicina equorum, sino también para establecer variantes textuales y estructurales en la transmisión del célebre manual de veterinaria ${ }^{16}$. Pero, además, las distintas piezas conocidas de la tradición de Ruffo son de innegable provecho para identificar y corregir lecciones erradas en cualquiera de los manuscritos e impresos que configuran la tradición de tan importante texto. Las páginas que siguen tienen por objeto revisar un pasaje de la traducción gallega del De medicina equorum, cuestionando las lecturas ofrecidas por los editores del texto y ofreciendo las claves necesarias para enmendar en la dirección adecuada las lecciones problemáticas del testimonio que hoy custodia la Biblioteca Nacional de España.

\section{UN LOCUS CRITICUS DE LA TRADUCCIÓN GALLEGA DE RUFFO: LECTIONES Y LECTURAS}

La traducción gallega de Ruffo ofrece una estructura que se asemeja a la del manuscrito latino transmitido por el códice veneciano editado por Girolamo Molin. A una sección inicial con nociones de hipolología - esto es, con indicaciones sobre cómo ha de engendrarse el caballo, cómo deben ser sus primeros cuidados, cómo hay que domarlo, alimentarlo, frenarlo y cabalgarlo, cómo ha de ser cada una de las partes de su cuerpo, etc.- le sigue otra, mucho más extensa, con conocimientos de veterinaria, donde a cada enfermedad con sus correspondientes remedios se consagra un capítulo ${ }^{17}$ : a un apartado VI encabezado por la rúbrica «Capitolo das enfirmidades e danaduras que véen ao cavalo acidentalmente de fóra» (1s. 364-365, § 6.0), en el que se ofrece el listado de las patologías (con la denominación latina y no gallega ${ }^{18}$ ) a las que después

${ }^{16}$ Sobre el particular vid. Montinaro (2010: 43-55; 2015: 35-62).

${ }^{17}$ Esta segunda sección constituye «l'essenziale del testo (circa 1'85\% del totale). L'opera è dunque prima di tutto un trattato di medicina veterinaria (ippiatria): l'esposizione delle regole di allevamento appare secondaria, e più marginale ancora la descrizione del cavallo» (Gaulin 1994: 429). Tan importante es esta parte de la obra que es la única que contienen algunos testimonios, como es el caso del ms. Nuove Accessioni 424 de la Biblioteca Nazionale Centrale de Florencia, del siglo XIV, que presenta el De medicina equorum «nella forma che di fatto si potrebbe definire 'breve', cioè limitata alla parte ippiatrica dell'opera. Infatti, il codice si apre con la tavole delle rubriche che riguardano le infermità del cavallo, per poi passare regolarmente in rassegna tutte le varie malattie. Segno evidente, quindi, che già nella prima metà del Trecento circolavano delle versioni ridotte dell'opera di Giordano Ruffo» (Bertelli 2009: 406). De otros manuscritos que presentan características estructurales análogas da cuenta Montinaro (2015: 158, 182-183, 213-214).

${ }^{18}$ Aunque no se puede considerar un argumento concluyente, el hecho de que, frente a lo que se observa en las otras versiones romances examinadas, el índice incluya los nombres de las enfermedades en latín (formas en ablativo, muchas de ellas considerablemente deturpadas, precedidas de la preposición de) podría apuntar que la fuente a partir de la que se elaboró la traducción gallega fue un manuscrito latino que debía de pertenecer a la misma familia que el códice que editó Molin, pues presenta la misma estructura que este, incluyendo aquella sección final que podría no formar parte del texto original de Ruffo (cf. n. 12). No 
se presta atención particularizada, le precede un pequeño capítulo $\mathrm{V}$ sobre las enfermedades que afectan al animal de forma natural, entre ellas las congénitas, y cuyo título es «Das enfirmidades naturaas e non naturaes que véen ao cavalo» $(1.336, \S 5.0)^{19}$. En este breve capítulo se encuentra uno de los pasajes que ofrece problemas en el texto gallego y que se presenta así en las diferentes propuestas editoriales:

\begin{tabular}{|c|c|c|}
\hline $\begin{array}{l}\text { DOMÍNGUEZ FONTELA } \\
(1938-1939,240: 399, \text { ls. 22-24) }\end{array}$ & $\begin{array}{l}\text { PENSADO TOMÉ } \\
(2004: 75, \text { ls. 18-19) }\end{array}$ & $\begin{array}{l}\text { PÉREZ BARCALA } \\
(2013: 154,1 \mathrm{~s} .348-350, \S 5.5)\end{array}$ \\
\hline $\begin{array}{l}\text { aas ueses naçe con alguas } \\
\text { sobeiedues de carne ou de } \\
\text { llandooas que se jeieeran } \\
\text { ontre o coiro et a carne et } \\
\text { son chamadas llandooas o } \\
\text { serosullas qe disen portas }\end{array}$ & $\begin{array}{l}\text { aas uezes naçe con algũas } \\
\text { sobeieduens de carne ou de } \\
\text { llandoas que se ieeran ontre o } \\
\text { coiro et a carne, et son cha- } \\
\text { madas llandooas o serosullas } \\
\text { que dizen porcas }\end{array}$ & $\begin{array}{l}\text { aas vezes nace con algũas } \\
\text { sobeg[e]dũes de carne ou de } \\
\text { landoas que se geeran ontre o } \\
\text { coiro e a carne, e son chama- } \\
\text { das landoas o[u] [e]scrofulas, } \\
\text { que dizen porcas }{ }^{20}\end{array}$ \\
\hline
\end{tabular}

Dejando a un lado las divergencias derivadas de los criterios gráficos utilizados en la presentación del texto - que en Domínguez Fontela y Pensado Tomé se pretenden fieles a una realidad manuscrita que hemos regularizado en nuestras propuestas-, las principales diferencias en la edición del pasaje reproducido afectan, por un lado, a la voz que hemos establecido como [e]scrofulas, distanciándonos de los editores precedentes, que conservan una imprecisa lección del manuscrito por ellos interpretada como serosullas, y, por otro, al sustantivo que lo glosa y que, frente a la lectura portas de Domínguez Fontela, en nuestras ediciones, al igual que en la de Pensado Tomé, se presenta como porcas.

\subsection{Serosullas versus escrofulas}

Como para otros loci critici problemáticos, las piezas de la tradición del De medicina equorum ofrecen los argumentos necesarios para valorar el problema textual que subyace en el manuscrito que transmite la versión gallega de Ruffo y atinar con su correcta interpretación. Es lo que sucede con el nombre que funciona como antecedente de la cláusula explicativa de relativo que lo glosa y que es reproducido por la pluma de Álvaro Eanes del siguiente modo:

obstante, al respecto de la fuente de la versión gallega del De medicina equorum Lorenzo (1993: 635) afirma que «não sabemos se o texto galego é uma versão directa do texto latino ou se houve entre ambos um intermediário noutra língua» y llega a sostener incluso que la traducción pudo haberse realizado «desde outra lingua peninsular e non directamente do latín» (Lorenzo 1998: 125). lin 1818: 19, 1s. 1-2).

${ }^{9}$ Más preciso es el título en el texto latino: «V. De aegritudinibus naturalibus venientibus» (Mo-

${ }^{20}$ En nuestra edición provisional del texto, incorporada como apéndice a la de Pensado Tomé, el pasaje no ofrece otra diferencia que la de presentar el nexo copulativo como et y no como e ( $c f$. Pérez Barcala 2004: 378, ls. 290-292). Cuando en el manuscrito la conjunción no aparece representada por medio del signo tironiano, se escribe con la forma latinizante $e t$, por lo que, según Lorenzo (1988: 80), el signo tironiano podría interpretarse como et o como $e$. No obstante, incluso cuando la copulativa está como et, hemos optado por presentarla siempre como $e$, ya que «la adopción de et para la conjunción copulativa [...] implicaría suponer una pronunciación de la -t final» (Sánchez-Prieto Borja 1998: 31). 


\section{Fipepilling}

Según ya se ha expuesto, esta lección manuscrita fue establecida como serosullas por el primer editor de la obra y esta lectura fue aceptada por Pensado Tomé, que define el sustantivo como «landres» (Pensado Tomé 2004: 331, s. v. serosullas) ${ }^{21}$. Si bien el valor semántico parece atinado, la lectura del vocablo como serosullas podría no ser más que una mala lectura de los editores tras la que podría haber un error de copia. Lo insólito es que el error no subsanado haya pasado a la lexicografía gallega, toda vez que, a partir de la edición de Domínguez Fontela, el término fue recogido en el inédito diccionario Frampas III de Elixio Rivas Quintas en los siguientes términos: «quiste seboso bajo la piel, en personas y animales. Se habla de as serosullas en el s. XIV, refiriéndose al caballo. (Trat. Albeitaría)» ${ }^{22}$.

La inapropiada inclusión de esta voz en la lexicografía parte de una inexacta transcripción de la lección que envía el manuscrito por parte del primer editor de la obra, que, no obstante, en una especie de fe de erratas que pasó inadvertida a los otros estudiosos, ya había constatado que la forma del códice es scrosullas, donde la segunda $s$ alta está por $f^{23}$, por lo que esta lección debe enmendarse por scrofullas ( $c f$. Domínguez Fontela 1940: 264$)^{24}$. Así las cosas, teniendo en cuenta que la grafía $l l$ representa la lateral $/ 1^{25}$, en virtud de la regularización gráfica adoptada en nuestras propuestas se edita [e]scrofulas, con la oportuna integración de la vocal protética, que debió de aparecer ya en el latín tardío para las voces que comenzaban con $s$ líquida ${ }^{26}$. Que esta es la interpretación adecuada y que, por lo tanto, serosullas (donde se lee como $e$ lo que es $c$ en el manuscrito ${ }^{27}$ ) es fruto de una mala lectura del testimonio lo apoya el hecho de que en el texto latino del que es traducción el gallego a ese vocablo le corresponda scrofu-

${ }^{21}$ Para el significado de landre, cf. DETEMA, s. v. landre: «Tumor del tamaño de una bellota que se forma en zonas glandulosas, como el cuello, los sobacos y las ingles».

${ }^{22} C f$. Elixio Rivas Quintas, Frampas III, contribución al diccionario gallego [inédito], s. v. serosulla. Los vocabularios gallegos se han consultado a partir del soporte electrónico coordinado por Santamarina (2003).

${ }^{23}$ Es bien conocido que algunos problemas en la lectura de los códices medievales tienen que ver con la «confusão entre certos grafemas bastante semelhantes na escrita. Casos de $f$ e $s$ (femina em vez de semina, deffiado em vez de desfiado), $n$ e $u$ (tornar em vez de toruar, noz em vez de uoz e viceversa), $c$ e $t$ (colheyto em vez de tolheyto, prescumeyro em vez de prestumeyro), $l$ e $s$ (trallado em vez de traslado), ni e $m$ (coonia em vez de cooma), nn e m (anno em vez de amo), ir e rr (teira em vez de terra), etc.» (Ferreira 2001: 73).

${ }^{24} \mathrm{El}$ notario de Baiona reproduce las dos letras de forma semejante, con la diferencia de que, frente a la $s$ alta $\left(\int\right)$, la $f$ presenta su hastil vertical cortado por un pequeño trazo horizontal. Para el diseño de ambas grafías por parte de otros amanuenses del siglo XV, vid. Tato Plaza (1999: 53 y 56) o Rodríguez Parada (2014: 23 y 38-39).

${ }^{25}$ En el manuscrito conviven $l$ y $l l$ tanto para la representación de $/ 1 /$ como para la de $/ 1 /$, de modo que ambos fonemas se igualan gráficamente ( vid. Pérez Barcala 2013: 122-125). Es, en efecto, bien sabido que, para la reprodución de $/ 1 /$, se utilizaban indistintamente $l$ y $l l$, grafias también empleadas, junto a otras (como lh, li o $l i i)$, para la palatal /1/: vid., por ejemplo, Maia (1986: 494-500).

${ }^{26}$ Vid. Ferreiro (1995: 161) o Lorenzo (1995: 660).

${ }^{27}$ No obstante, $c$ y $e$ son también dos de esas grafias que en algunos trazados pueden confundirse. Vid., por ejemplo, Tato Plaza (1999: 51-52) o Rodríguez Parada (2014: 31 y 32). 
lae, que se traduce respectivamente como scrufuli y scruofoli en las versiones siciliana e italiana examinadas ${ }^{28}$ :

aas vezes nace con algũas sobeg[e]dũes de carne ou de landoas que se geeran ontre o coiro e a carne, e son chamadas landoas o[u] [e]scrofulas, que dizen porcas

VERSIÓN quando equus nascitur cum aliquibus superfluitatibus carnium; velut glandu-

LATINA lae, quae fiunt inter corium et carnem, et hae glandulae, sive scrofulae, aut testudines vulgariter nuncupantur (Molin 1818: 19, 1s. 21-24)

VERSIÓN alcuni fiati E naxinu adossu altri infirmitati di li quali glanduli oi scrufuli si SICILIANA chamanu oi testuini (De Gregorio 1905: 576, 1s. 13-15)

VERSIÓN alquante fiate li nasceno adosso altre infermitade, le quali si chiamano granITALIANA dole uvero scruofoli usia testudine (Olrog Hedvall 1995: 73, 1s. 310-311)

Por otro lado, para interpretar correctamente la forma paleográfica erróneamente presentada como serosullas hay que tener en cuenta que el De medicina equorum consagra a la patología un capítulo específico que, sin embargo, la traducción gallega omite como consecuencia de una laguna de proporciones considerables que afecta al códice en su tercer cuaderno, del que, además de otros elementos materiales, se habrían perdido los dos bifolios centrales $^{29}$. La ausencia del referido capítulo, que tampoco se anuncia en el índice con los nombres de las enfermedades que se desarrollan en la sección veterinaria del texto, no permite saber cómo habría aparecido escrito ahí el vocablo para el que se presentan las dificultades de lectura en el pasaje que estudiamos. En efecto, entre los capítulos perdidos como consecuencia de la mencionada laguna se incluiría el paralelo al latino «De ceteris glandulis et cura», que tiene equivalencia en las otras versiones consideradas del tratado de Ruffo, excepto la siciliana ${ }^{30}$, y en cuya exposición aparece de nuevo la voz scrofulae (con correspondencia en las diferentes traducciones):

\begin{tabular}{|c|l|}
\hline $\begin{array}{c}\text { VERSIÓN } \\
\text { LATINA }\end{array}$ & $\begin{array}{l}\text { De ceteris glandulis et cura } \\
\text { De ceteris vero superfluitatibus carnium quae naturaliter nascuntur intus } \\
\text { corium et carnes quae dicuntur vulgariter glandulae sive testudines aut scro- } \\
\text { fulae nuncupantur; [...] (Molin 1818: 111, ls. 15-19) }\end{array}$ \\
\hline $\begin{array}{l}\text { VERSIÓN } \\
\text { ITALIANA }\end{array}$ & $\begin{array}{l}\text { Dele ghiandule \& dele loro cura .1xviiij. } \\
\text { Dell'autre superfluità dela carne che naturalmente nasceno alcuna volta tra l' }\end{array}$ \\
\hline
\end{tabular}

${ }^{28}$ En las otras versiones revisadas el pasaje se adapta sin introducir el término o se advierten particularidades estructurales que lo omiten. La primera circunstancia se constata en la traducción occitana — «E alcunas ves nays anbe alcunas superfluitas carnosas aynssins quant grandolas entre cuer e carn, que son vulgarmens appelladas lymaces» (Arquint 2006-2007: 115, § 5.4; para la insólita voz lymaces con el significado 'escrófulas', cf. Ibid.: 389, s. v. lymassa) — o en la francesa transmitida por el ms. $S$ — «Et aucune fois il avient que en aucune partie dou cors sunt fetes superfluités de char ausi comme glandes desous le cuir» (Prévot 1991: $128, \S 151$ ) - toda vez que en otros testimonios franceses se dan diferencias textuales y estructurales considerables (cf. Ibid.: 45-47 y 127-129).

${ }^{29}$ Para las lagunas del manuscrito, vid. Pérez Barcala (2013: 72-73).

${ }^{30}$ Esta versión concluye en el fol. $41 \mathrm{v}$ del manuscrito sin dar por terminada la exposición del tratamiento para las «inchouaturi ki nun toccanu lu uiuu di llunghia» (De Gregorio 1905: 605, 1. 18) y sin incluir, por tanto, los capítulos posteriores, entre los que se encontraría el correspondiente al latino «De ceteris glandulis et cura».

${ }^{31}$ El capítulo es también anunciado en el listado de las patologías con el que se abre la sección veterinaria: «Dele ghiandule \& dele loro cura .lxviiij» (Olrog Hedvall 1995: 78, 1. 409). 


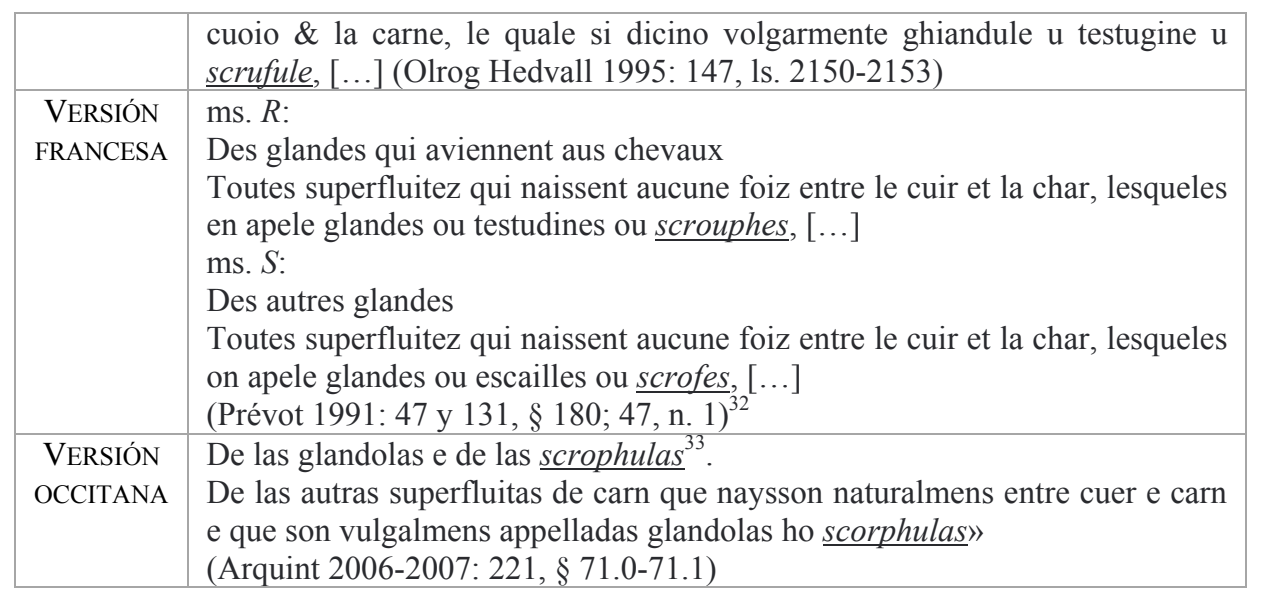

\subsection{Portas versus porcas}

La voz hace referencia a un nódulo subcutáneo originado por una inflamación de los ganglios linfáticos ${ }^{34}$ sobre cuya exposición en el De medicina equorum Patrizia Arquint comenta que no se da una localización precisa:

la veterinaria antica, come la medicina umana, conosce il termine scrofola per un ingrossamento delle ghiandole del collo, eventualmente da identificarsi, in campo veterinario, con l'adenite equina [...]. Si noti però che Giordano non specifica la localizzazione delle scorphulas e tratta l'adenite equina sotto il termine di estrangolhon (Arquint 2006-2007: 451, s. v. estrangollon $)^{35}$.

${ }^{32}$ A partir de la edición de Prévot, reconstruimos los pasajes de ambos testimonios $(R$ y $S)$, los únicos que incluyen la voz en cuestión y el correspondiente título. A diferencia de lo que sucede en las otras versiones de Ruffo, en los elementos revisados de la tradición francesa el capítulo no se incluye en la sección VI del tratado, sino que se presenta como parte del desarrollo de la sección V, según puede verse en Prévot (1991: 45-47).

${ }^{33}$ El capítulo es también anunciado en el índice con el que comienza la adaptación occitana: «De las glandolas e de las scorphulas fo. .lxvj.» (Arquint 2006-2007: 93, tav. 71).

${ }^{34}$ Trolli (1990: 34, s. v. scrofulae) define el término como «ingrossamento delle ghiandole linfatiche» y Moulé (1913: 441, s. v. escrouelles) como «des ganglions lymphatiques hypertrophiés». Poulle-Drieux (1966: 56) describe lo que Ruffo denomina testudo o scrofula como «kystes congénitaux sébacés, sudoripares ou dermoïdes».

${ }^{35}$ La etiología y sintomatología del stranguillionis son así expuestas por Ruffo en el capítulo asignado a esa patología: «Sunt et aliae aliquae glandulae circa caput equi cujuslibet exsistentes, quarum aliquae sub gutture equi jacent, quae inflantur vel accidentaliter augmentantur propter humores capitis equi frigidati. Ad dictas glandulas de capite descendentes, ex grossione vel inflatione quarum totum guttur inflatur, et ita constringunt meatus gutturis, unde equus, prout convenit, vix poterit exspirare, et etiam male bibit et comedit, et haec aegritudo vulgo dicitur strangullionis» (Molin 1818: 50, 1s. 6-14). El capítulo se adapta así en la traducción gallega: «Son outras landoas que cada ũu cavalo ha a par da cabeça, das quaes jazen alguas so o goto do cavalo. E incha[n]se ás vezes e crecen por razon dos homores que decen [d]a cabeça do cavalo, que é fria. Da grosedõe e do inchaço delas ínchase todo o goto e asi se aperta que adur pode espirar o cavalo, e bebe mal e come mal por esta razon. E a tal enfirmidade chaman estrangullo» (ls. 541-546, § 10.1-10.2). 
Si bien la versión gallega de Ruffo omite el término equivalente al latino testudines, presente en el pasaje estudiado en las otras adaptaciones revisadas, glosa el sustantivo [e]scrofulas por medio de una cláusula de relativo en la que se introduce otro vocablo que trata de aclarar el significado de aquel y que se presenta así en el manuscrito:

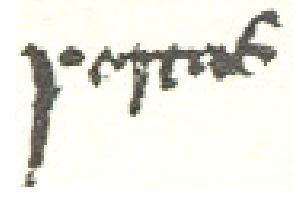

Como se ha indicado más arriba, este otro sustantivo fue transcrito como portas por Domínguez Fontela, si bien la lectura correcta es porcas, según fue bien entendido por Pensado Tomé, que definió la voz como «puercas, escrófulas» (Pensado Tomé 2004: $304, s . v$. puercas). Lo que subyace en la lección manuscrita es un fenómeno paleográfico, el de la confusión de $c$ y $t^{36}$, del que el códice ofrece otros ejemplos que la tradición de Giordano Ruffo contribuye a interpretar en la dirección correcta ${ }^{37}$. No obstante, en el caso que ahora nos ocupa, los testimonios consultados del De medicina equorum no ayudan a determinar si la confusión de las grafías $t$ y $c$ ha de resolverse como portas (según propone el primer editor del Tratado de Alveitaria) o como porcas (según se presenta en las siguientes ediciones del texto), pues el término no ofrece correspondencia en las piezas revisadas del tratado del calabrés. Aunque no puede descartarse que la voz se encontrase en la fuente latina a partir de la que se hizo la traducción gallega, el hecho de que esta abunde en cláusulas de relativo que introducen voces que pretenden aclarar el alcance semántico de otras, y que tampoco se localizan en la tradición consultada de la obra, podría sugerir que tales glosas fueron incorporadas por el traductor y no se encontraban en la fuente, por lo que no resulta fácil determinar cómo pudo conocer aquel el nuevo término ${ }^{38}$. Las observaciones que siguen buscan ofrecer datos que legitimen porcas - y no portas - como la auténtica lección del códice y que contribuyan a determinar las motivaciones semánticas que pudieron propiciar la utilización de dicho nombre para referirse a las escrófulas. Las puntuales consideraciones que aquí se

${ }^{36}$ Para la semejanza del trazado de $c$ y $t$, véase, por ejemplo, Tato Plaza (1999: 52 y 56).

${ }^{37}$ Uno de los casos más llamativos — aunque no el único- es el de esa lección que Pensado Tomé presentó como peta, dando origen a una explicación semántica que carece de sentido. Si se advierte que el término que en su lugar figura en el pasaje latino correspondiente es petia, todo apunta que la lectura correcta es peca, con el uso de la grafía $c$ para la africada predorsodentoalveolar (resultante del grupo -Tj-) comúnmente representada como $c$, siendo, en efecto, peça la interpretación ofrecida para la ambigua lección manuscrita por Domínguez Fontela y nosotros mismos: «E val aas vezes a esta enfirmidade o fumo da peça queimada» (1. $888, \S 22.6)$. Para explicar este particular y concretar el valor semántico del vocablo afectado por el problema paleográfico vid. Pérez Barcala (2016).

${ }^{38}$ Este tipo de glosas son frecuentes en el texto para adaptar el léxico botánico-farmacéutico: así, por ejemplo, «espelta, que quer dizer melga» (ls. 118-119, § 3.9), «branca ursina, que chaman gigante» (1. 622, $\S 14.3)$, «paritaria, que é a[1]fevega de coovra» (1. 622, § 14.3), «mercurial, que é ortiga» (1. 623, § 14.3), «sarro da cuba, que chaman tartaro» (1. 972, § 25.6), «alosna, que é asente» (1. 1087, § 30.6), «encenço branco, que chaman macho» (1. 1160, § 34.6), «greda, que e gales» (1. 1259, § 43.15), «fenum grecum, que quer dizer alforva» (1. 1275, $\S 44.5)$, «esquilla, que quer dizer cebola alvarraãa» (1. 1276, § 44.5), «termentina, que semella algedran» (1s. 1276-1277, § 44.5), «piritro mudo, que é azeche» (1. 1489, § 53.11), «piretro, que quer dizer azeche» (ls. 1517-1518, § 54.8), «engu, que semella sebugo» (1. 1511, § 54.6). Consideraciones sobre períodos explicativos de este tipo pueden verse en Herrera (1992) o Pérez Pascual (1992). 
presentan no pretenden otra cosa que proporcionar algunas de las claves necesarias para la correcta interpretación de la forma manuscrita como porcas a partir de algunas calas en la lexicografía - en particular en la española, al encontrarse en esta el término paralelo puercas con el significado apuntado, 'escrófulas'-, así como en algunos textos médicos latinos que dan cuenta del porqué del uso de la voz porca con tal acepción.

\subsubsection{Un recorrido por la lexicografía}

Por lo que se refiere a la presencia de porca en gallego con el valor semántico que se estudia, es de destacar que la del Tratado de Alveitaria constituye la única documentación conocida del vocablo con el significado de 'escrófula' en la lengua gallega, tanto medieval como moderna, según se desprende de la consulta del TMILG y del TILG. Lo que esta última base de datos registra con dicho valor es la voz alporca, para la que, no obstante, ofrece tres documentaciones muy tardías que proceden de una misma obra, $O s$ biosbardos, de Eduardo Blanco Amor, de 1962. Con todo, la lexicografía gallega ( $c f$. Apéndice I) ${ }^{39}$ recoge el nombre con anterioridad, aunque no antes del siglo XX, pues se hace un hueco por primera vez en el diccionario de la RAG (1913-1928), que define alporca como término del lenguaje médico que designa el «Tumor de las glándulas que suele reventar y convertirse en llaga: escrófula de las glándulas del cuello: bocio». A partir de ahí, el sustantivo es incorporado por Carré en las sucesivas ediciones de su diccionario (la $1^{\text {a }}$ data de 1928-1933) y por trabajos lexicográficos posteriores que redundan en su valor semántico de 'escrófula ${ }^{40}$. Para designar esta misma realidad, los diccionarios gallegos incluyen otros sustantivos, además de los ya comentados alporca y escrófula. A la voz estruma, que se introduce en Filgueira (1926) y otros trabajos que le siguen, y a cuya familia pertenece el adjetivo estrumoso (sinónimo, pues, de escrofuloso), se suma el sustantivo lamparón, que, como se verá más abajo, es común en español para designar la escrófula: si bien el término tiene su primer registro en Cuveiro (1876), su presencia en el ámbito lexicográfico gallego se conoce desde que, en el siglo XVIII, Sobreira (1970c) definió la escrofularia como «Herva dos lamparós» ${ }^{41}$.

Si en gallego no existe porca sino alporca con la acepción aquí estudiada, y solo desde fechas relativamente recientes, el portugués, que también desconoce porca, permite establecer, no obstante, una cronología más antigua para alporca, tanto en lo que se refiere a sus documentaciones textuales como lexicográficas, a la vez que proporciona otros pormenores que no son irrelevantes en el estudio de ese vocablo como sinónimo de escrófula. Lejos de toda pretensión de una exhaustividad que la oportuna

${ }^{39}$ Un recorrido por la lexicografía gallega, desde los fundacionales Bocablos Gallegos Escuros del bachiller Olea del siglo XVI hasta las aportaciones de Cuveiro Piñol en el XIX, puede verse en el póstumo trabajo de Pensado Tomé (2014). La panorámica puede completarse con el «Limiar» que presenta el recurso electrónico de Santamarina (2003), disponible en línea en <http://sli.uvigo.es/DdD/documentos/ddd_ limiar.pdf $>$.

${ }^{40}$ El Diccionario galego de termos médicos, elaborado por la Real Academia de Medicina e Cirurxía de Galicia (Santiago de Compostela, Consellería de Educación e Ordenación Universitaria, 2002) y disponible en el Corpus Técnico do Galego $(C T G),<$ http://sli.uvigo.es/CTG/>, define así alporca: «Escrófula dos ganglios do pescozo que pode rebentar e converterse en chaga».

${ }^{41}$ Cf. también el siguiente apunte de Lis Quiben (1949: 311): «Lamparón de los caballos.- Le llaman así a las Escrófulas y las curan lavándolas con agua donde se lavó un matrimonio recién casado». 
consulta del Apéndice II busca subsanar, se proporcionan a continuación los detalles que, bajo el lema alporca(s) u otros en los que el término concurre, presentan algunos diccionarios, tanto monolingües como bilingües (con especial atención a los que contrastan el portugués con el latín y con el castellano). El sustantivo alporca(s) se documenta desde los orígenes de la tradición lexicográfica portuguesa, que, como se sabe, se sitúan en el siglo XVI con glosarios bilingües que ofrecen la equivalencia latina para las palabras portuguesas y viceversa ${ }^{42}$. En ellos, para alporca se proporciona, además de scrophula/scrofula, la denominación latina struma, a cuya familia léxica pertenecían los adjetivos strumaticus o strumosus, según informan, en efecto, los primeros glosarios latino-portugueses (Jerónimo Cardoso, Agostinho Barbosa y Bento Pereira) y repiten otros, más tardíos, de la misma índole (António Franco, Carlos Folqman o Pedro José da Fonseca). Sin embargo, otros diccionarios aportan registros del sustantivo que son anteriores a sus primeras documentaciones lexicográficas (que, según acaba de decirse, remontan al siglo XVI): aunque Bluteau o Morais ofrecen ejemplos de alpor$c a(s)$ que proceden de obras datadas entre los siglos XVII y XIX, según el DELP de Machado el registro más antiguo está en un texto del siglo $\mathrm{XV}^{43}$.

Además de contribuir a la datación de alporca(s), la lexicografía portuguesa establece, obviamente, el alcance del término con definiciones que, más o menos exten$\operatorname{sas}^{44}$, vienen siempre a ofrecer para él el significado de 'escrófula' y para escrófula el

\footnotetext{
${ }^{42}$ Para una historia de la lexicografía portuguesa, vid., por ejemplo, Verdelho y Silvestre (2007) o Vázquez Diéguez (2011a).

${ }^{43}$ El ejemplo recogido por Machado — «...e esta monja... era doente de Alporcas em tal maneira que a não julgauão senão aa morte...»- procede de la Crónica de Cinco Reis de Portugal, conservada en el códice 886 de la Biblioteca Municipal do Porto, del siglo XV, y cuya edición diplomática se debe a Artur de Magalhaes Basto (Porto, Livraria Civilizaçaão, 1945). También Cunha, Nova Fronteira, y Houaiss, Dicionário, documentan el término desde el siglo XV, siendo el primer autor la fuente de la que el segundo extrae la documentación más antigua de alporca, que es el IVPM = António Geraldo da Cunha, Índice do Vocabulário do Português Medieval, Fundação Casa de Rui Barbosa - suplemento [A-C] (in Confluência Revista do Instituto da Língua Portuguesa e do Liceu Literário Portugués, no 3, separata, Rio de Janeiro, 1992). Esa misma documentación es también la que consta como más antigua en Cunha $(2014$, s. v. alporca). Otros lexicógrafos localizan la palabra en textos posteriores: Bluteau, Vocabulario, s. v. antistrumâtico, la documenta en un pasaje de las Observaçoens Medicas Doutrinaes de cem Casos gravissimos de João Curvo Semedo (1635-1719), aunque en esta obra y en otras del mismo autor (como la Polyanthea medicinal: noticias galenicas e chymicas o las Observationes aegritudinum fere incurabilium) el término ofrece cuantiosas ocurrencias, entre las que se hallan, por ejemplo, las recogidas también en Bluteau, Vocabulario, s. v. folliculo, orgevaoã, vincetôxico, zuche; la $10^{\mathrm{a}}$ edición de Morais, Grande dicionário, s. v. alporca, recoge documentaciones que se encuentran en la História de São Domingos, de Frei Luís de Sousa (1556-1632), y en la novela Eusébio Macário de Camilo Castelo Branco (1825-1890), que vio la luz en 1878, si bien en Moraes, Diccionario da Lingua, s. v. alpórca, se aduce un ejemplo que procede del Sermão da Publicação do Jubileu del Padre António Vieira (16081697), de 1654, también incluido, s. v. alporca, en la $G E P B$, que registra la voz, asimismo, en otro relato de Castelo Branco, O filho natural.

${ }^{44}$ Tras la apariencia de diccionario bilingüe portugués-latín de Bluteau, Vocabulario, se esconde una obra de carácter casi enciclopédico que constituye un punto de referencia fundamental en el conjunto de la lexicografía portuguesa ( $c f$. Silvestre 2008): además de exponer el significado de alporca y sus diferencias con respecto a otras tumoraciones, se manifiesta por vez primera al respecto de las motivaciones semánticas que determinaron el uso de tal voz para nombrar la enfermedad, «porque he ordinaria nos porcos» (cf. infra), y proporciona información sobre la práctica de los reyes franceses en el tratamiento de este mal. Este último detalle lo recogen también algunos diccionarios españoles para el lema lamparón (que, según consta en el Apéndice III, es otro de los términos conocidos desde los orígenes de la lexicografía castellana para denominar
} 
de 'alporca', de modo que, reduciendo la definición de una y otra voz a una simple identificación semántica, ambos lemas se presentan como intercambiables, pues escrófulas «He o nome latino de Alporcas», según refiere Bluteau (Vocabulario, s. v. escrófulas), y alporca es el «Nome vulgar das escrófulas», según constatan Morais (Grande dicionário, s. v. alporca) o Coelho (Diccionario Manual, s. v. alporca) y reiteran Chernoviz (Diccionario de medicina popular, s. v. escrophulas) - «As escrophulas chamam-se vulgarmente alporcas»- o Silva Bastos (Diccionario etymologico, s. v. alporca) — «designação vulgar das escrófulas»-

El corpus consultado de la lexicografía en lengua portuguesa permite sentar las bases de un campo semántico del que forman parte las voces estruma $a^{45}-\mathrm{y}$, en relación con esta, también antistrumático/antiestrumático, estrumoso, estrumose, estrumosidade o estrumite-, escrófula — con la que han de conectarse el adjetivo (y también sustantivo) escrofuloso y los nombres escorfulárialescrofulária, escrofulismo, escrofulose- y alporca — con sus derivados alporquento y alporcado-.

Este conjunto lexicográfico es, asismismo, de gran utilidad para aclarar el origen y las motivaciones semánticas de la palabra que se estudia. En esta dirección, Constancio (Novo Diccionario critico) y Faria (Novo Diccionario) se muestran elocuentes al señalar que alporca procede de una voz latina porca precedida de la forma árabe del artículo $(a l)^{46}$, y otras contribuciones permiten entender por qué se creó dicha base latina: Machado (DELP, s. v. alporca) sugiere que el hecho tiene que ver con que porca es «decalque do lat. scrofula, "porquinha", diminutivo de scrofa, "porca"»" ; Houaiss (Dicionário), que incide en dicha idea, hace hincapié, asimismo, en las motivaciones semánticas que determinaron el empleo de escrófula y alporca para nombrar la patología, pues, según el lexicógrafo, la primera voz procede «do lat. scrofūlae, arum 'escrófulas (enfermidade)', dim. de scrōfa,ae 'porca'; parece que a relação da enfermidade com o nome-base se deve ao fato de os porcos terem sido, com freqüência, sujeitos a esta moléstia; cp. etim. de alporca», y, del mismo modo, la segunda deriva de «al- + porca,ae 'porca', pois, segundo se cria no passado, o porco era muito sujeito a esta moléstia; $c f$. scrōfa, ae 'porca' e scrofūlae, arum 'escrófula (enfermidade)'». El dato ya se encontraba en Bluteau (Vocabulario, s. v. alporca), para quien la denominación alporca tiene que ver con el hecho de que la «enfermidade assim chamada [...] he

las escrófulas), como s. v. puede verse, por ejemplo, en Oudin 1607, Covarrubias 1611, Franciosini 1620, Trognesius 1639, Sobrino 1705. Sobre la presencia en la historiografía europea del motivo de la curación de las escrófulas en la Edad Media por el conctacto de las manos de los reyes cristianos de Francia e Inglaterra vid. Bloch (2007). El médico español Diego Álvarez Chanca, en su Tractatus de fascinatione, de 1499, también atribuye tales virtudes al rey Afonso V de Portugal (vid. Salmón y Cabré 1998: 60 y n. 57).

${ }^{45}$ Ciertos lexicógrafos explican el porqué del uso de tal nombre, que remonta al latino struma (de abonada presencia en los diccionarios bilingües latín-portugués), para designar este concepto: $c f$., por ejemplo, Bluteau, Vocabulario, s. v. alporca — «truma, ae Fem. Cic. Cels. \& Plinio as vezes dizem struma no singular, \& outras vezes strumae no plur. segundo certo Etymologista, chamaõlhe os latinos Strumae â struendo, quia structum assurgunt, quippe tumor gladularum ex impacto humore crasso»—; Constancio, Novo Diccionario critico, $s$. v. alporca — «Em Lat. struma de struor, $i$, elevar-se, formar eminencia»-; Faria, Novo Diccionario, s. v. alporca $\longrightarrow$ Em Lat. struma de struor, $i$, formar eminencia, elevar-se»-

${ }^{46}$ Para la voz como arabismo, vid. Corriente (2003, s. v. alporca).

${ }^{47}$ La lexicografía bilingüe latín-portugués constata con frecuencia este valor semántico de scrofa, según puede verse en el citado Apéndice II. 
ordinaria nos porcos», y es reiterado en Constancio (Novo Diccionario critico, s. v. escrofulas) o Faria (Novo Diccionario, s. v. escrofulas) —cuando comentan que escrófula deriva del lat. scrofula, que era «dim. de scrofa, porca», y que el uso de este nombre para indicar la dolencia se debe a la circunstancia de que «as porcas são sujeitas ás alporcas»-, así como en Cunha (Nova Fronteira, s. v. alporca) — que hace derivar alporca del nombre porca, con el que se designaba la hembra del cerdo, «provavelmente porque este animal é muito sujeito a essa doença»—o en Machado (DELP, s. v. escrófula) - que ve en el empleo de esta denominación «mais um vestigio da analogia com os tumores ganglionares da porca»-

La existencia de una base etimológica porca, que constituye el origen de las voz alporca, común al gallego y al portugués, y que tiene su fundamento en la red de asociaciones semánticas expuestas, viene ratificada por la lexicografía castellana ( $c f$. Apéndice III) $^{48}$. Por un lado, los glosarios bilingües que contrastan voces portuguesas y castellanas $^{49}$ son reveladores al respecto, en tanto que muestran que a la palabra portuguesa alporca(s) corresponde en castellano, además del ya mencionado lamparón ${ }^{50}$, el sustantivo puerca: así, en Bluteau, Diccionario Castellano y Portuguez, se incluyen las entradas «Lamparones. Alporcas», «Puerca. Alporca» ( $c f$. Apéndices II y III); y en Bluteau, Tabla, la de «Alporcas. Lamparones» (cf. Apéndice II). Antes de Bluteau tales identidades ya habían sido constatadas en Pereira, Prosodia, con la entrada «struma, ae, a alporca, lamparón [...]» (cf. Apéndice III, vid. igualmente la nota con la que se comenta este mismo vocabulario en el Apéndice II), y después de Bluteau, Mascarenhas Valdez, Diccionario español-portugués, redunda en ello al señalar que a los vocablos castellanos escrófula y lamparón corresponden indistintamente los portugueses alporcas y escrofula ( $c f$. Apéndice II). Las equivalencias registradas ratifican, sin lugar a dudas, la afinidad de las denominaciones castellanas escrófula, lamparón $\mathrm{y}$, la que más nos interesa, puerca, para referir el proceso patológico que, además de escrófula, tiene alporca como equivalencia lusa.

Por otro lado, la lexicografía española certifica que el nombre puerca es de abonada presencia en los diccionarios con el significado estudiado y que es en ella donde se localiza su más antigua documentación: esta se encuentra precisamente en el Diccionario latino-español de Nebrija 1492, donde se lee, en efecto, que la voz latina scrophula es la utilizada para la enfermedad llamada puerca en castellano: «scrophula, ae, por la puerca, dolencia» ${ }^{51}$. Si en este corpus se recogen, por lo tanto, los más remotos regis-

${ }^{48}$ Para la historia de la lexicografía española (en particular la de los orígenes), vid. el capítulo dedicado a las «Fuentes» en Nieto Jiménez y Alvar Ezquerra (2007, I: XXXV-XCIII).

${ }^{49}$ Sobre la lexicografía bilingüe español-portugués, vid. Messner (2008) o Vázquez Diéguez $(2008,2011 b)$. Por su propia naturaleza, en el Apéndice final estos glosarios pueden incorporarse en el II o en el $I I I$, o en ambos.

${ }^{50}$ El vocablo aparece ya en Nebrija 1495 ? y a partir de ahí su presencia es constante en la lexicografía española, según constata la consulta del Apéndice III. Sobre las razones semánticas que subyacen a la utilización de lamparón se pronuncian, s. v., lexicógrafos como Covarrubias 1611 «[...] en Castellano se puede dezir lamparon [...], splendor, porque la cutis del lamparon tiene vn cierto resplandor albicante, por estar tan estirado, y por su corrosion»--, de quien se toma el dato en Academia Autoridades (G-M) 1734.

${ }^{51}$ Que en este glosario bilingüe del humanista sevillano (1441-1522) se halla el primer registro del término es una realidad constatada por Alonso (1958, s. v. puerca); según el estudioso, con el significado de 
tros del vocablo en español con este significado a finales del siglo XV en Nebrija, fuera de este tipo de textos las documentaciones son más tardías. En el DETEMA se encuentran ejemplos de escrófula y otros sinónimos, entre los que están landre - que, recordemos, es el término con el que Pensado Tomé había definido las mal editadas serosullas en lugar de escrófulas (cf. supra 2.1) - y lamparón — que, insistimos, es la voz que, además de ser ofrecida en algunos diccionarios gallegos y portugueses como equivalente de alporca, la lexicografía española introduce de forma recurrente en la definición de puerca, como ya hemos ido señalando, y que el mismo DETEMA define como «escrófula»-, pero no se recoge el sustantivo puerca $^{52}$. En el CORDE, las primeras documentaciones de este vocablo proceden de obras del siglo XVI, concretamente de la Historia de yerbas y plantas con los nombres griegos, latinos y españoles (1557-1567), de Juan de Jarava, y del Tratado de la esencia, causa y curación de los bubones y carbuncos pestilentes (1600), de Manuel de Escobar. El primero de los textos refiere las propiedades de algunas plantas para curar la enfermedad, mientras que el segundo explica el origen y las motivaciones semánticas de su denominación:

\begin{tabular}{|c|c|}
\hline $\begin{array}{l}\text { Historia de yerbas y plantas } \\
\text { con los nombres griegos, } \\
\text { latinos y españoles }\end{array}$ & $\begin{array}{l}\text { Tratado de la esencia, causa y curación de los bubones y } \\
\text { carbuncos pestilentes }\end{array}$ \\
\hline $\begin{array}{l}\text { Ranunculus septimum. Ra- } \\
\text { núnculo seteno } \\
\text { [...] Los polvos del seteno } \\
\text { ranúnculo hazen esternudar. } \\
\text { Los erbolarios la llaman } \\
\text { algunas vezes strumea, por- } \\
\text { que es buena contra strumas, } \\
\text { que son puercas o lamparones } \\
\text { o hinchazones de las landre- } \\
\text { zillas. } \\
\text { Oxalis. Azederas. } \\
\text { Viene en huertos, prados y } \\
\text { otros lugares. Haze resolver } \\
\text { las landrezillas o puercas y } \\
\text { los hinchazones tras las ore- } \\
\text { jas, si las cozieren en vino y } \\
\text { después la pusieren encima. }\end{array}$ & $\begin{array}{l}\text { es justo se sepa que este nombre, scrophula es griego, y en } \\
\text { realidad, de verdad, la tal enfermedad se llamó assí por la } \\
\text { similitud y semejança con la scropha, que quiere dezir 'la } \\
\text { puerca', porque ésta de ordinario pare cinco o seys o más } \\
\text { lechones, assí, ni más ni menos, la scróphula se halla de } \\
\text { ordinario con cinco o seys o más, y pocas veces con menos, } \\
\text { d'estos tumores, lo qual no acontece en las glándulas o } \\
\text { nudos porque quando éstos tales más se descomiden, no } \\
\text { salen de dos arriba, y las scrófulas, por lo menos, nacen } \\
\text { tres; o se llama así por ser enfermedad natural a los puercos } \\
\text { y que de ordinario la tienen. Pero no me agrada tanto esto, } \\
\text { porque si assí fuera, no se llamara puerca solamente, antes } \\
\text { se llamara puerco, que es a quien, a lo uno y a lo otro, } \\
\text { comprehende, y assí, no dudo que se dizen assí solamente } \\
\text { por la semejança que tienen con la puerca al parir, diga lo } \\
\text { que quisiere Plinio en su Natural hystoria, libro II, capítulo } \\
\text { 33, que yo he visto en otros animales, fuera del puerco y } \\
\text { del hombre, scrófulas. } \\
\text { Esta mala hazienda siempre es engendrada y hecha de } \\
\text { humores crassos, crudos y glutinosos, y quedan metidas en } \\
\text { sus membranas, y ansí en ellas embueltas, complicándose }\end{array}$ \\
\hline
\end{tabular}

'escrófula', puerca se documenta desde el siglo XV: «s. XV al XX. Escrófula. Nebrija Dicc. esp.-lat., 1492, s. v.». También en un trabajo del lexicógrafo lebrijano encuentra este valor metafórico el $D C E C H$, s. v. puerco: «Figuradamente "puercas, como lamparones: scrofulae" Nebr.» (referencia en la que es posible ver una remisión a Nebrija 1495? según se constata en el Apéndice III).

${ }_{52}$ Cf. DETEMA, s. v. escrófula, landre, lamparón. Otras voces que este recurso incluye con el valor semántico de 'escrófula' en los tratados médicos antiguos en castellano son pulte y nudo. 


\begin{tabular}{ll|l}
$\begin{array}{l}\text { porque sana las puercas o } \\
\text { lamparones }\end{array}$ & $\begin{array}{l}\text { con venas y artherias, tienen assiento en las cuerdas y nier- } \\
\text { vos de la garganta, donde tanto se arraygan que parece casi } \\
\text { impossible el poderlas sacar, especialmente las que topan } \\
\text { con el niervo recurrente y la vena jugular, que siendo tantas } \\
\text { las que nacen, pocas veces se escapan de tocar en estos } \\
\text { niervos y venas, y como se enfieltran y entrapan tanto en } \\
\text { ellas, no se pueden sacar ni curar sin que a las tales venas y } \\
\text { nievos venga daño y qualquiera que les viniere será gran- } \\
\text { díssimo para el paciente. }\end{array}$ \\
\end{tabular}

Además de ofrecer la documentación más antigua del término, la lexicografía española, en particular la monolingüe, suele dar el significado de puercas como «cierta especie de tumóres à modo de lamparónes» — según lo define Academia Autoridades $(O-R)$ 1737, y de modo análogo diccionarios posteriores, que, como algunos anteriores, ofrecen también para el vocablo las correspondencias latinas struma(ta) y scrophulao como «escrófula» sin más — conforme se lee, por ejemplo, en Toro y Gómez 1901-. Los trabajos lexicográficos bilingües (donde se contrasta el castellano con el latín u otra lengua europea) o plurilingües (en los que se confronta el castellano con el latín y/o el griego y/o otras lenguas) inciden en que puerca era una alternativa léxica de lamparón para nombrar la realidad designada por la voz griega choeras y las latinas struma ${ }^{54}$ o scrofa/scropha ${ }^{55}$. Una claridad meridiana arroja en este sentido, una vez más, Nebrija en el Lexicon que añadió a la edición de la traducción del De materia medica de Dioscórides realizada por Juan Ruelio y que, supervisada por el humanista, vio la luz en $1518^{56}$ : «choeras, adis, morbus qui latine struma siue scropha, hispane

${ }^{53}$ Conviene destacar que algunos diccionarios, más allá de referir los usos medicinales de estas plantas, aluden en particular a su utilización para el tratamiento específico de las escrófulas: $c f$. ., por ejemplo, Bluteau, Vocabulario, s. v. ranúnculo — «Planta, cujo nome se deriva de Rana, porque de ordinario nasce como a Rãa, em lugares humidos, \& auguas encharcadas, [...] Outros lhe chamaõ Herba scelerata, [...] Herba strumea, porque tem virtude para resolver alporcas, a que os Latinos chamaõ Struma. [...]. Todos estes Ranunculos contem muyto sal acrimonioso, \& corrosivo, mataõ o gado que come delles; usa-se delles exteriormente contra a Tinha, Alporcas, \& excrescencias da carne. [...]»-; Zerolo 1895, s. v. celidonia menor — «Hierba, especie de ranúnculo, [...] "Llaman algunos escrofularia á la celidonia menor, porque aplicada en forma de emplastro resuelve los lamparones" (LAG.)»-

${ }^{54}$ Aunque entre los textos médicos antiguos en castellano incorporados al DETEMA no se incluye la voz estruma, sí se documenta en ellos la variante (e)strumón, que está presente en el Compendio de la humana salud, del siglo XV - «el strumon o inchazon que se haze en el pescuezo»- y cuyo significado es, efectivamente, establecido como «Lamparón, escrófula en el cuello» (DETEMA, s. v. estrumón). Al igual que en gallego y portugués, a partir de estruma se creó en castellano una familia léxica de la que forman parte voces como estrumífero, estrumitis, estrumosidad, estrumoso, etc.

${ }^{55}$ Del diminitivo scrofula/scrophula deriva en castellano la tantas veces mencionada voz escrófula, de fecunda aparición en los diccionarios que, como puede verse en el Apéndice III, cuando no se prodigan en su definición, se limitan a identificarlo semánticamente con las tantas veces citadas lamparón y puerca. Como en gallego y portugués, pertenecen a la familia léxica de escrófula en castellano términos como escrofuloso, escrofularia, escrofúlide, escrofulismo, escrofulosis, etc.

${ }^{56}$ Este vocabulario griego, latino y español, añadido por Nebrija a la edición de esta traducción de Dioscórides, se suma al proyecto de elaborar un diccionario de medicina que anunciaba en el prefacio a su Lexicon iuris ciuilis de 1506 y del que algunas entradas aparecen intercaladas en la edición del Dictionarium latino-hispanicum, publicada en Amberes en 1545. Sobre el alcance de Dioscórides en el trabajo lexicográfico del humanista andaluz y la importancia por él concedida al vocabulario médico, vid. Carrera de la Red (1997, 
puercas», «scrofa, ae, siue choeras, adis, latine struma, hispane puerca o lamparón», «struma latine, graece vocantur choeras, adis, hispane puerca o lamparón» (cf. Nebrija 1518 , s. v. $)^{57}$.

Al igual que sucede en algunos vocabularios portugueses, las relaciones entre el nombre de la enfermedad y el cerdo no se ocultan en ciertos diccionarios castellanos que, con explicaciones de distinto tipo, permiten entender cuáles pudieron ser las motivaciones semánticas que determinaron el uso de puerca con el valor que se estudia: así, por ejemplo, en Covarrubias 1611, s. v. lamparón, se ofrecen varios detalles, entre los que se encuentra el de que «Esta enfermedad es ordinaria en los puercos, y assi tomò el mombre dellos» y, de igual modo, Rodríguez Navas 1918, s. v. escrófula, comenta que dicha voz procede «Del lat. scrofulae, de scrofa, la puerca paridera, que suele sufrir esta enfermedad» ${ }^{58}$; a la exigua información que facilitan estos lexicógrafos, ha de sumarse la singular explicación que, en su afán por dar detalles sobre la procedencia de las palabras castellanas, suministra Rosal 1601, s. v. puerca, al poner en relación el nombre de la enfermedad así llamada con las acumulaciones de tierra que con el hocico hacían los cerdos: «Puerco de porco latino, y éste de las porcas, que hacen con el hocico; y así aporcar hacer aquellas porcas, que son montoncillos de tierra cavada, y por la semejanza de éstas se llaman puercas unas hinchazones, como lamparones o flemones, enfermedad». A este curioso comentario puede añadirse el Tratado de Manuel de Escobar, que, como ya se ha señalado, expone las motivaciones semánticas que se ocultan tras el empleo de puerca para designar la escrófula del siguiente modo:

la tal enfermedad se llamó assí por la similitud y semejança con la scropha, que quiere dezir 'la puerca', porque ésta de ordinario pare cinco o seys o más lechones, assí, ni más ni menos, la scróphula se halla de ordinario con cinco o seys o más, y pocas veces con menos, d'estos tumores, lo qual no acontece en las glándulas o nudos porque quando éstos tales más se descomiden, no salen de dos arriba, y las scrófulas, por lo menos, nacen tres; o se llama así por ser enfermedad natural a los puercos y que de ordinario la tienen. Pero no me agrada tanto esto, porque si assí fuera, no se llamara puerca solamente, antes se llamara puerco, que es a quien, a lo uno y a lo otro, comprehende, y assí, no dudo que se dizen assí solamente por la semejança que tienen con la puerca al parir, diga lo que quisiere Plinio en su Natural hystoria, libro II, capítulo 33, que yo he visto en otros animales, fuera del puerco y del hombre, scrófulas ${ }^{59}$.

2001) Perona (2008) o Guerrero Ramos (1992): en esta última contribución se recogen concretamente las voces griegas y latinas del Lexicon incorporado a la edición de Dioscórides para las que el humanista ofrece la equivalencia castellana.

${ }^{57}$ Para la presencia de la voz castellana puerca (y también lamparón) en el léxico añadido por el lebrijano a la la edición de Dioscórides, $c f$., en efecto, estas mismas entradas en Guerrero Ramos (1992: 35, $\S$ $250 ; 42, \S 334)$.

${ }^{58}$ En la lexicografía bilingüe que contrasta el latín y el castellano (y en la inversa), y puntualmente otras lenguas, al igual que en la análoga portuguesa ( $c f$. n. 47), se constata también que este era el significado de scrofa, como puede verse en muchas de las entradas del Apéndice III.

${ }^{59}$ En el capítulo LI del libro VIII de la Naturalis historia, Plinio el Viejo (siglo I) dice que la porcina «es una especie expuesta a enfermedades, sobre todo anginas y escrófulas» (citamos por la traducción 


\subsubsection{Algunos textos médicos medievales}

Del examen de la lexicografía examinada pueden extraerse, a modo de recapitulación, varios datos, de los que los más relevantes para nuestro estudio son los siguientes: (a) para designar la inflamación de los ganglios linfáticos (en particular los del cuello) el latín conoció, además de scrofula, el término struma, y uno y otro dejaron descendientes en gallego, portugués y castellano también en voces que derivan de ellos; (b) además de escrófula y estruma (y otras voces entre las que se encuentra el recurrente lamparón de la lexicografía castellana), esas mismas lenguas utilizaron para designar el mismo concepto un vocablo que tiene su base en una forma latina porca, a la que remonta puerca en castellano y alporca en portugués y gallego; (c) la aparición de la voz porca de la que derivan esos resultados ha de ponerse en relación con la circunstancia de que scrofula sea diminutivo de scrofa, sustantivo que nombraba a la hembra del cerdo $^{60}$; (d) a la implantación de porca debió de contribuir la conexión que existía entre la dolencia y la especie porcina, según se infiere de explicaciones semánticas diversas en las que se menciona al cerdo o a la hembra.

Cuanto el corpus lexicográfico consultado desvela puede documentarse con un puñado de pasajes de textos médicos latinos que pretende ser tan solo una muestra significativa de las razones que pudieron contribuir a la implantación de porca como voz paralela de scrofula. Como ya ha sido apuntado, struma era el término con el que en latín clásico se designaba la enfermedad a la que en este trabajo nos venimos refiriendo $^{61}$. Según Bertier (1991: 307), dicho vocablo, struma, fue después desplazado por scrofa y scrofula, dando cuenta el Medicinae Liber de Cassius Felix, de mediados del siglo $\mathrm{V}$, del empleo de scrofa como designación de la inflamación de los ganglios linfáticos del cuello y de las razones por las que ese fue el vocablo elegido para nombrar la dolencia:

XXVI. Ad scrofas

1. Scrofas Graeci chiriadas uocant duritias rotundo schemate natas et neruis atque arteriis uenis et musculosis membris connaturatione infixas, quod Graeci catasynfysin uocant. Et cum glandulosis in locis in utraque gutturis parte fuerint natae, sicuti sues feminae turgida colla cum dolore ostendunt, unde ipso nomine scrofae uocantur. Et sunt curatione difficiles. Nascuntur in cacochymis corporibus id est mala humore possesis.

2. Est iterum aliud genus scrofarum minime adhaerentes sed magis sub cute natantes et plurima natione pullulantes sicut genus porcorum, unde iterum scrofae nomen acceperunt. Nascuntur ut supra dictum est glandulosis in locis, ut in gut-

castellana de Cantó et al. 2002: 143), en un pasaje inspirado, al parecer, en el capítulo XXI del libro VIII de la Historia animalium de Aristóteles, dedicado a las enfermedades del cerdo.

${ }^{60}$ No hay que olvidar que scrofa es en italiano el nombre con el que se designa a la 'cerda', aunque desde el siglo XIV ese mismo término, al igual que sucedía en latín (cf. n. 63), también está documentado para designar el proceso patológico de la escrófula: cf. DEI, s. v. scrofa ${ }^{1}$, scrofa $^{2} ; T L I O$, s. v. scrofa.

${ }^{61}$ Comenta Grmek (1991: 211-212) que struma «est un terme latin classique, attesté depuis Cicéron et employé par Celse, mais signifiant une tumeur scrofuleuse du cou, c'est-à-dire les écrouelles, scrofulae des anciens vétérinaires et du latin médical moderne (infection tuberculeuse des ganglios lymphatiques du cou)». 
ture uel sub ala aut in inguine, et sunt siue chirurgia siue medicamentis curatione faciles (Fraisse 2002: 51-52) ${ }^{62}$.

A la elocuencia con la que el fragmento reproducido del médico romano se pronuncia al respecto de la utilización de scrofa para designar tanto a la hembra del cerdo como al proceso patológico ${ }^{63}$, se pueden sumar las explicaciones ofrecidas por algunos estudiosos a propósito de la exposición que ciertos textos médicos dan de la dolencia. Así, por ejemplo, en el compedio de medicina del autor bizantino Pablo de Nicea, cuya cronología se sitúa entre los siglos VII y IX-X, se dedica el capítulo 116 a una enfermedad sobre la que Ieraci Bio (1996: 374, n. 116.1) comenta lo siguiente:

Probabilmente è una malattia di origine tubercolare che provoca l'ingrossamento delle ghiandole linfatiche. Semanticamente il termine è collegato dagli antichi ai maiali (per la presenza di ghiandole tumefatte sulle mandibole o per la loro prolificità paragonabile a quella dell'affezione) [...]. Il termine latino è struma (CELS., V 28.7) o scrofa (Cass. Fel., $26=42,15-43,15$ Ros.) ${ }^{64}$.

Del mismo modo, Michael R. McVaugh proporciona detalles de interés para el análisis de la relación entre la denominación de la dolencia (scrophula) y el animal cuando glosa la información vertida por el médico francés Guy de Chauliac, del siglo XIV, en el capítulo IV del tratado II de su Chirurgia magna - «scrophula ad modum scrophe porcine plurificata, dura, non omnino separata, in collo plurimum reperta» (McVaugh

${ }^{62}$ El subrayado es nuestro. El pasaje citado es así traducido al francés por Fraisse (2002: 51-52): «XXVI. Contre les scrofules. 1. Les Grecs appellent "chiriades" les scrofules, indurations de forma arrondie fixées aux nerfs, aux artères et aux muscles congénitalement, et comme dissent les Grecs, "catasynfysin". Et lorsqu'elles sont nées à l'endroit des glandes, de chaque côté de la gorge, les malades présentent un cou gonflé comme les truies et douloureux, voilà pourquoi on les appelle de ce nom de "scrofa". Et elles sont difficiles à traiter. Elles se déclarent dans les corps "cacochymes", c'est-à-dire en proie à une humeur mauvaise. 2. Il existe par ailleurs un autre genre de scrofules qui ne sont pas fixes mais plutôt flottent sous la peau et pullulent en une portée très nombreuse comme la race des porcs, de là le nom de "scrofa" qu'elles ont reçu. Elles naissent, comme il a été dit plus haut, à l'endroit des glandes, par exemple à la gorge, sous l'aisselle ou à l'aîne, et son faciles à traiter, soit par la chirurgie, soit par des médicaments».

${ }^{63}$ Con ambos valores se recoge el nombre en $D E L L$, s. v. scrōfa, $-a e, \ll 1^{\circ}$ truie. [...]; $2^{\circ}$ écrouelles (Mul. Chir.)». El pasaje de la Mulomedicina Chironis, del siglo IV, donde se encuentra el vocablo corresponde al capítulo XIII del libro II: «Quodcunque iumentum strumas uel parotidas uel scrophas habuerit, sic eum intelliges. tumor dextra sinistra ab auricula usque ad fauces grandis increscet, et recto capite erit prouocabitur simile modo ut ab stranguria. sic eum curabis [...]. si tamen parotide uel strume in callositate permanserit, urito punctis cauteris. usta curato et malagma imponito, que est ex calce et a[u]xungia composita, quam in dinamidiis habes. sanum fiet similiter curabis et scropha $<\mathrm{S}>$ supra dictas utile est» (Niedermann 1910: 8-9). Repárese en la similitud de estas palabras con las de la Digesta Artis Mulomedicinae de Vegecio, que dedica el capítulo 23 de su libro II a la escrofulosis equina designada con la voz latina struma y que reproducimos en la traducción de la obra realizada por Robles Gómez (1999: 187-188): «Muchas veces infestan la garganta de las caballerías estrumas, parótidas, o escrófulas, que se manifiestan por la hinchazón de sus fauces. Entonces tienen la cabeza estirada hacia arriba y se agohan como por entrangulamiento». Sobre el valor semántico de struma, comenta el mismo Robles Gómez que «era el término clásico para referirse a la "escrofulosis", una infección tuberculosa de los ganglios linfáticos del cuello».

${ }^{64} \mathrm{El}$ texto griego y la correspondiente traducción italiana pueden verse respectivamente en Ieraci Bio (1996: 206-207 y 345). Cf. también los datos que proporciona Mazzini (1989: 131, § 705 y n. 140) sobre la raíz scrofol(o)-: «scrofol(o)-, 1. scrofúlae, ārum, a: SCROFOLA, a. (lett. [tumefazione del collo] simile a quella della scrofa)»; «In latino la forma plurale [sic scrofulae] evidenzia le singole manifestazioni esteriori, cioè i noduli che prediligino il collo del malato e lo fanno assomigiliare, in qualque modo, a quello del maiale». 
1997, I: 88$)^{65}$ - y da cuenta de algunos textos medievales en los que se constata el vínculo entre el nombre de la afección y la especie porcina. Dice, en efecto, McVaugh (1997, II: 82):

Althoug Guys does not explain how scrofulas resemble sows, the explaniation given in other medieval works are that sows often suffer from scrofula, that they have many offspring, and that scrofulosus swellings look like little pigs; cfr. $\mathrm{Ca}$ non IV. 3.2.9 (440ra); Reg. disp. I.8.11 (96va); and Bruno II.7 (ed. pp. 249$250)^{66}$.

De las obras mencionadas por McVaugh, la que ofrece una cronología más antigua es la que cita como Regalis dispositio: si bien bajo este nombre se oculta la versión que, en la primera mitad del siglo XII, Esteban de Antioquía llevó a cabo de la summa de Haly Abbas, de la segunda mitad del siglo X, a Constantino el Africano (ca. 10101087) se debe otra traducción de la obra del médico persa que, difundida con el título Liber Pantegni y datada en la segunda mitad del siglo XI, se inscribe en el marco de la introducción de la medicina árabe en Occidente desarrollada por el célebre autor cuando entra en la abadía benedictina de Montecassino ${ }^{67}$. En la Theorica del Pantegni la scrofula es así definida por el Africano:

Scrofula est apostema quasi glans nascens in molli carne colli aut in ea quae est sub ascellis vel inguinibus, maxime autem in prora colli vel in latere sui [...], quare scrophula vocatur, quia in collis porcorum sepe nascuntur vel dicunt alii utpote scropha multos porcellos generat, ita haec in numero augmentata, nomen a simili est sortita ${ }^{68}$.

La de Haly Abbas fue la obra más influyente en la medicina medieval hasta que, en la segunda mitad del siglo XII, vio la luz la traducción al latín del Canon de Avicena (980-1037) realizada en Toledo por Gerardo de Cremona (1114-1187) ${ }^{69}$. El capítulo IX

${ }^{65}$ En la anónima traducción castellana del tratado, de finales del siglo XV, el pasaje se adapta del siguiente modo: «la scrofula a manera de la scrofa porcina es multiplicada, dura, no del todo apartada: en el cuello por las mas vezes fallada» (apud CORDE).

${ }^{66}$ Glosarios médicos latinos como el Lexicon medicum de Stephanus Blancardus, además de describir la enfermedad, informan del porqué del uso de ese vocablo para designarla: «Scrofvla, seu strvma, [...], quia porcas infestare solent, sunt tumores p. n. glandularum colli, vel aurium, renitentes, propria tunica contenti, oriundi a materia secreta in folliculis glandulosis, stagnante in cauo ob frigus, ductus emittens constringens, $\&$ partes indurans, vel quia materia exitui inepta, orbatur tenuissimo suo vehiculo. [...]». La cita, en la que se ha destacado el pasaje de interés, procede de Stephani Blancardi Lexicon Medicvm renovatvm in qvo totivs artis medicae vocabvla vsitata breviter et dilvcide explicantvr, Halae Magdeburgicae, Apud Io. Gottl. Bierwirth, 1748, pp. 604-605, s. v. scrofvla. [<http://www.uni-mannheim.de/mateo/camenaref/blanckaert.html>]).

${ }^{7}$ Sobre la importancia de Constantino para el conocimiento de la medicina árabe en Occidente y su método de trabajo, vid. Gabrielli (1967), De Martino (1988), Jacquart y Micheau (1990: 87-129), Montero Cartelle (1990), Montero Cartelle y Herrero Ingelmo (1998-1999). Sobre el Pantegni en particular consúltese Burnett y Jacquart (1994).

${ }^{68}$ Se cita la obra a partir del impreso, que la difundió a nombre de Isaac y que vio la luz en Lyon en 1515: cf. Omnia opera Ysaac, Lugduni, in officina probi viri Iohannis de Platea, 1515, vol. II, fol. 38va, 1. $58 \mathrm{ss}$. El subrayado es nuestro.

${ }^{69}$ El Canon fue uno de los muchos textos árabes traducidos por Gerardo de Cremona, que adaptó, además, y entre otros, tratados como el Liber ad Almansorem de Razes, el manual de cirugía de Albucasis o la obra de Serapión. Para la actividad traductora de Gerardo de Cremona consúltese Jacquart (1989, 1990), Jac- 
del Canon en la traducción de Gerardo de Cremona trata de scrofulis y ofrece sobre la dolencia estos detalles:

Scrofule similantur nodis, sed differunt ab eis in hoc quod non sunt separate, sicut nodi, immo sunt suspense cum carne. Et plurimum quidem accidunt in carne molli [...]. Et loca in quibus generantur plures scrofule sunt collum et subascelle. Et videtur quod non nominantur scrofule nisi propterea quod multum accidunt porcis, propter gulositatem eorum aut propterea quod figure earum secundum plurimum assimilantur porcis ${ }^{70}$.

Poco relevante es, a la luz de este pasaje, la información que proporciona el otro autor mencionado por McVaugh, pues, en el capítulo VII del libro II de su Cyrurgia, Bruno da Longobardo o de Calabria, a mediados del siglo XIII, no hace más que copiar a Avicena, a quien cita de forma explícita ${ }^{71}$.

Al repertorio de obras médicas que relacionan semánticamente el nombre de la enfermedad (scrofula) con el animal (cerdo) pueden sumarse más textos que los referidos por el editor de la Chirurgia de Guido de Cauliaco. Así, por ejemplo, el italiano Teodorico Borgognoni (1205-1298), autor también de un manual de veterinaria con notables influencias del de Ruffo, redactó a mediados del siglo XIII un tratado de cirugía; en el capítulo XXIII del libro III de dicha obra, inspirándose también en Avicena, expone el obispo de Cervia que «dicuntur scrophule, sicut dicit Auicena, quia multum accidunt porcis propter gulositatem ipsorum $\rangle^{72}$. Otro pasaje que puede sumarse a los recogidos es el del capítulo V del libro II de la Praxis medicinalis de Arnau de Vilanova (ca. 1240-1311):

Scrophulae itaque sunt quasi glandulae in molli carne nascentes vt in gula sub ascellis vel in inguinibus [...], \& dicuntur scrophulae ad similitudinem propter scrophas. Nam sicut scrophae quandoque .vij. vel .viij. filios pariunt, ita \& scrophulae simili modo quandoque .v. vel .viij. vel plures vel pauciores quandoque in vno loco nascuntur. [...]. Scrophulae vero nunquam ad minus in minori numero trium in vno loco ${ }^{73}$.

quart y Micheau (1990: 147-160). Sobre el papel desempeñado en la difusión de la medicina árabe por Constantino el Africano en Salerno y por Gerardo de Cremona en Toledo vid. Montero Cartelle (2005).

${ }^{70}$ Cf. Avicenne Liber Canonis medicine cum castigationibus Andree Bellunensis (translatus a magistro Gerardo Cremonensi in Toleto ab Arabico in Latinum), Venetiis, in edibus Luce Antonii Iunta Florentini, 1527. El descatado es nuestro.

${ }^{71}$ El pasaje dedicado a las scrophule en el texto de Bruno, médico de Padua y Verona en el siglo XIII, puede leerse en Cyrurgia Guidonis de Cauliaco. De balneis porectanis. Cyrurgia Bruni. Theodorici. Rolandini. Rogerii. Lanfranci. Bertapalie. Iesu Hali de oculis. Canamusali de baldac de oculis, Venetiis, impressum per Gregorium de Gregoriis, 1513, fol. 89vb. El fragmento en cuestión ha sido traducido así al italiano por Tabanelli (1970: 84): «E non sono chiamate " scrofule", como dice Avicena, se non perchè queste avvengono nei maiali per la loro golosità, ma perchè la loro figura, secondo la maggior parte delle volte assomigilia al maiale, o perchè di una ne avvengono in maggior numero».

${ }^{72}$ Se cita por el impreso de Venecia de 1513 (que incluye también la referida Cyrurgia de Bruno) mencionado en la nota precedente: cf. Cyrurgia Guidonis de Cauliaco. De balneis porectanis. Cyrurgia Bruni. Theodorici, fol. 121ra.

${ }^{73}$ Citamos a partir de la edición impresa de Lyon, 1586: $c f$. Arnaldi Villanovani summi philosophi et medici excellentissimi. Praxis medicinalis, Lvgdvni, apud Antonivm Tardif, vico mercatorio, 1586, fol. 54, col. a. El subrayado es nuestro. 
Los textos presentados abundan para explicar las razones que pudieron dar origen a una forma porca para designar la patología de la que venimos tratando. De la existencia de la misma como sinónimo de escrófula y de los porqués de su utilización nos ponen al tanto los pasajes de algunas obras producidas en el entorno de la escuela médica de Salerno, a la que Federico II dio un notable impulso y cuya influencia en la redacción del inaugural tratado de veterinaria de Giordano Ruffo ha sido aducida por algunos estudio$\operatorname{sos}^{74}$. Sumamente esclarecedora es la entrada correspondiente a scropha en el glosario conocido como Alphita, probablemente de la primera mitad del siglo XIII:

SCROPHA, id est, porca; inde scrophula, apostema quod maxime nascitur sub gula vel sub ascellis et in inguinibus, quia nunquam invenitur illud apostema solum, sed multiplex, quemadmodum scropha raro habet unum solum fetum (García González 2007: 296, 1s. 112-115) ${ }^{75}$.

El referido glosario salernitano fue una de las fuentes manejadas para la redacción de otro texto de contenido similar, la obra lexicográfica del siglo XIV conocida como Sinonimia delos nombres delas medeçinas griegos e latynos e arauigos, que incluye otras entradas igualmente reveladoras:

Scofa o escrofula, i. puerca quod sicut porca habet multos filios, ita vna multas ginit (?) uel filii (?) sunt sonate, et dicitur in vulgari lamparones (Mensching 1994: 149 , 1s. $1-5)^{76}$

Stafu .i. scrofula (.i. lamparon, .i. puerca) (Mensching 1994: 148, 1s. 27-28)

\section{REFERENCIAS BIBLIOGRÁFICAS}

ALONSO, Martín (1958): Enciclopedia del Idioma, Madrid, Aguilar.

ARQUINT, Patrizia (2006-2007): Il volgarizzamento occitanico del Liber de medicina equorum di Giordano Ruffo: edizione critica, Universita degli Studi di Siena, tesi di dottorato (XXI ciclo) [inédita].

${ }^{74}$ «Nonostante dunque il comprensibile generale silenzio dei trattati di medicina del tempo su questioni inerenti la patologia animale, era molto probabile che di fatto i medici salernitani possedessero al riguardo numerose nozioni. Ma anche a prescindere da questo, se si considerano le affinità esistenti tra la fisiologia umana e quella animale, è evidente che la veterinaria non avrebbe potuto trovare un terreno cosí favorevole come all'ombra di una scuola medica di tanto prestigio» (Trolli 1990: 22).

${ }^{75}$ El editor señala analogías entre esta entrada del glosario botánico-farmacéutico y la Clavis $\mathrm{Sa}$ nationis de Simón de Génova, de finales del siglo XIII, del siguiente modo: «Scropha < lat. scrofa (Pall. 105, 2), "puerca paridera", "marrana". Etimología correcta del término scrophula < lat. scrofula, mejor en plur. scrofulae, "escrófulas", "paperas" o "lamparones", es decir, la tumefacción de los ganglios linfáticos. Cfr. Sim. Ian. 55rb: Scrophule a scropha dicte eo quod vt a scropha multi porcelli ita ad vna multa pullulant, similiter et greci chiradas, a chira .i. porci vocant» (García González 2007: 535-536).

${ }^{76}$ Para la sección inicial de la entrada («Scofa o escrofula, .i. puerca»), la lectura que transmite la Sinonimia en el ms. 3370 de la Biblioteca Nacional de Madrid es «Scrofa, i. porca, et inde dicitur scrofula» (Mensching 1994: 149, n. 112). Por otro lado, el editor de la obra establece paralelismos entre el pasaje citado y la mencionada entrada del Alphita, en particular en la versión de este texto conservada por el ms. latin 6964 de la Bibliothèque Nationale de France, del siglo XV: «apostemma quod maxime nascitur sub gula uel sub assellis et in inguinibus, quia numquam inuenitur id apostema solum, sed multiplex, sicut nec scropha solum habet fetum sed multos» (Mensching 1994: 149, n. 113). 
BERTELLI, Sandro (2009): «La Mascalcia di Giordano Ruffo nei più antichi manoscritti in volgare conservati a Firenze», en V. Ortoleva y M. R. Petringa, eds., La Veterinaria antica e medievale (testi greci, latini e romanzi). Atti del II Convegno internazionale (Catania, 3-5 ottobre 2007), Lugano, Lumières Internationales, pp. 389427.

BERTIER, Janine (1991): «Les noms des lésions corporelles d'origine interne d'après le $D e$ Medicina de Celse (V 28)», en G. Sabbah, ed., Le latin médical. La constitution d'un langage scientifique. Réalités et langage de la médecine dans le monde romain. Actes du IIIe Colloque international «Textes médicaux latins antiques» (Saint-Étienne, 11-13 septembre 1989), Saint-Étienne, Publications de l’Université de Saint-Étienne, pp. 296-308.

Bloch, Marc (2007): I re taumaturghi, Torino, Einaudi (1 ${ }^{\mathrm{a}}$ ed., Paris, 1924).

BURnetT, Charles y Danielle JACQUART, eds. (1994): Constantine the African and 'Alì ibn al- 'Abbās al-Magǔsī: the Pantegni and related texts, Leiden, E.J. Brill.

CANTO, Josefa et al. (2002): Plinio. Historia Natural, Madrid, Cátedra.

CARRERA DE LA RED, Avelina (1997): «Dioscórides en la obra médica de E. A. de Nebrija», en J. M. Maestre Maestre, L. Charlo Brea y J. Pascual Barea, coords., Humanismo y pervivencia del Mundo Clásico. Homenaje a Luis Gil, Cádiz, Universidad de Cádiz-Ayuntamiento de Alcañiz, I, pp. 121-128.

CARrera de la ReD, Avelina (2001): Aelii Antonii Nebrissensis Dictionarium medicvm (El Diccionario médico de Elio Antonio de Nebrija), introducción, edición y glosario de Avelina Carrera de la Red, Salamanca, Universidad de Salamanca.

$C L P=$ Corpus Lexicográfico do Portugués, <http://clp.dlc.ua.pt>.

CORDE $=$ REAL ACADEMIA ESPAÑOLA, Corpus Diacrónico del Español, <http://www.rae.es/ recursos/banco-de-datos/corde>.

CORRIENTE, Federico (2003 ${ }^{2}$ [1999]): Diccionario de arabismos y voces afines en iberorromance, Madrid, Gredos.

CunHa, Antônio Geraldo da (2014): Vocabulário histórico-cronológico do Português Medieval, Rio de Janeiro, Fundação Casa de Rui Barbosa, 2 vols.

DCECH = COROMINAS, Joan y José Antonio PASCUAL (1980-1991): Diccionario crítico etimológico castellano e hispánico, Madrid, Gredos, 6 vols.

DE GREGORIO, Giacomo (1905): «Il codice de Cruyllis-Spatafora, in antico siciliano, del sec. XIV, contenente la Mascalcia di Giordano Ruffo», Zeitschrift für romanische Philologie, XXIX, pp. 566-606.

DEI = BATTISTI, Carlo y Giovanni Alessio (1950-1957): Dizionario Etimologico Italiano, Firenze, G. Barbèra Editore, 5 vols.

$D E L L=$ ERNOUT, Alfred y Antoine MEILLET (1985 ${ }^{4}$ [1932]): Dictionnaire étymologique de la langue latine. Histoire des mots, Paris, Klincksieck.

De Martino, Anna (1988): «Constantino Africano», en M. Pasca, ed., La Scuola Medica Salernitana. Storia, immagini, manoscriti dall'XI al XIII secolo, Napoli, Electa Napoli, pp. 50-67.

DETEMA = HERRERA, $\mathrm{M}^{\mathrm{a}}$ Teresa, dir. (1996): Diccionario Español de Textos Médicos Antiguos, Madrid, Arco Libros, 2 vols.

Di CosTA, Giuseppina (2000-20001): Edizione di un inedito volgarizzamento in siciliano medievale della Mascalcia di Giordano Ruffo, Università degli Studi di Catania, tesi di laurea [inédita]. 
Dominguez FontelA, Juan (1938-1939): «Tratado de Albeitaria por Jordan Rubio, de Calabria», Boletín de la Comisión de Monumentos de Orense, XI, 238, pp. 302309 ; 239, pp. 345-352; 240, pp. 395-402; 241, pp. 451-458; 242, pp. 495-502; 243, pp. 543-550.

DomingueZ FonTELA, Juan (1939-1940): «Tratado de Albeitaria por Jordan Rubio, de Calabria», Boletín de la Comisión de Monumentos de Orense, XII, 244, pp. 13-20; 245, pp. 93-100; 246, pp. 109-115.

Dominguez Fontela, Juan (1940): «El Códice de Albeitería de Alvaro Eans o Yans da Seira. Epílogo», Boletín de la Comisión de Monumentos de Orense, XII, 251, pp. 261-264

FERREIRA, José Azevedo (2001): «A transmisso do texto medieval», en O. Lopes y M. de F. Martinho, dirs., História da Literatura Portuguesa. Volume 1 (Das Origens ao Cancioneiro Geral), Lisboa, Alfa, pp. 67-75.

FERreIro, Manuel (1995): Gramática histórica galega. I. Fonética e Morfosintaxe, Santiago de Compostela, Edicións Laiovento.

FICHERA, Aldo (2013): «I due trattati di mascalcia in volgare siciliano del ms. 2934 della Biblioteca Riccardiana di Firenze: problematica delle fonti», Bollettino del Centro di studi filologici e linguistici siciliani, 24, pp. 55-85.

FICHERA, Aldo (2014-2015): L'edizione dei due trattati di mascalcia in volgare siciliano del codice 2934 della Biblioteca Riccardiana di Firenze, Università degli Studi di Catania, tesi di dottorato [inédita].

Fraisse, Anne $\left(2002^{2}\right.$ [2001]): Cassius Felix, De la medecine, texte établi, traduit et annoté par Anne Fraisse, Paris, Les Belles Lettres.

GABRIELli, Francesco (1967): «La medicina araba e la Scuola di Salerno», Salerno. Hyppocratica Civitas, I, 3, pp. 12-23.

Garcia GonZalez, Alejandro (2007): Alphita. Edición crítica y comentario, Firenze, Sismel-Edizione del Galluzzo.

GAUlin, Jean-Louis (1994): «Giordano Ruffo e l'arte veterinaria», en P. Toubert y A. Paravicini Bagliani, eds., Federico II e le scienze, Palermo, Sellerio Editore, pp. 424-435.

GEPB = Grande Enciclopédia Portuguesa e Brasileira, Lisboa, Editorial Enciclopédia, 1978-2004.

GRMEK, Mirko D. (1991): «La dénomination latine des maladies considérées comme nouvelles par des auteurs antiques», en G. Sabbah, ed., Le latin médical. La constitution d'un langage scientifique. Réalités et langage de la médecine dans le monde romain. Actes du IIIe Colloque international «Textes médicaux latins antiques» (Saint-Étienne, 11-13 septembre 1989), Saint-Étienne, Publications de l’Université de Saint-Étienne, pp. 195-214.

GUERRERO RAMOS, Gloria (1992): «Anotaciones de Nebrija a Dioscórides: voces españolas», Boletín de la Real Academia Española, t. LXXII (cuaderno CCLV), pp. 7-50.

${ }^{77}$ Del trabajo de Domínguez Fontela, publicado en los mencionados números del Boletín de la Comisión de Monumentos de Orense, hay edición facsimilar digitalizada: Grupo Marcelo Macías de colaboradores do Museo e Arquivo Provincial de Ourense / Xunta de Galicia, Consellería de Cultura, Promoción Social e Turismo, Dirección Xeral de Promoción Cultural, [2004], 1 DVD-ROM (= Patrimonio bibliográfico de Galicia. Serie facsimilar; 1). 
HERRERA, $M^{a}$ Teresa (1992): «Los nombres de las plantas medievales y su verdadera identidad», en J. A. Bartol Hernández, J. F. García Santos y J. de S. Guervós, eds., Estudios filológicos en homenaje a Eugenio de Bustos Tovar, Salamanca, Universidad de Salamanca, I, pp. 445-453.

HIEPE, Thomas (1990): Das «Buch uber die Stallmeisterei der Pferde» von Jordanus Ruffus aus dem 13. Jahrhundert (Abschrift, Ubersetzung und veterinärmedizin-historische Bewertung), München, Tierärztlichen Fakultat der Ludwig-MaximiliansUniversitat [Inaugural-Dissertation zur Erlangung der tiermedizinischen Doktorwürde].

HunT, Tony (2011): Old French Medical Texts, Paris, Classiques Garnier.

IERACI BIO, Anna Maria (1996): Paolo di Nicea. Manuale medico, Napoli, Bibliopolis.

JACQUART, Danielle (1989): «Remarques préliminaires a une étude comparée des traductions médicales de Gérard de Crémone», en G. Contamine, ed., Traduction et traducteurs au Moyen Âge (Actes du Colloque International du CNRS organisé à Paris, Institut de recherche et d'histoire des textes les 26-28 mai 1986), Paris, Éditions du CNRS, pp. 109-118.

JACQUART, Danielle (1990): «Les traductions médicales de Gérard de Crémone», Annali della Biblioteca statale e libreria civica di Cremona, 41, pp. 57-70.

JACQUART, Danielle y Françoise MICHEAU (1990): La médecine arabe et l'Occident médiéval, Paris, Maisonneuve \& Larose.

Juarez Blanquer, Aurora y Antonio Rubio Flores (1991): Partida Segunda de Alfonso X el Sabio. Manuscrito 12794 de la B.N., Granada, Impredisur.

KlEIN, Lieselotte (1969): Studien zur «medicina equorum» des Jordanus Ruffus (1250), Inaugural-Dissertation zur Erlangung des Grades eines Doctor Medicinae Veterinariae, Hanovre.

LA RosA, Michela (1999-2000): Edizione di un inedito volgarizzamento in siciliano medievale della mascalcia di Giordano Ruffo (cod. Riccardiano 2934, cc. 35-58), Università degli Studi di Catania, tesi di laurea [inédita].

LIS QUIBEN, Víctor (1949): La medicina popular en Galicia, Pontevedra, Gráficas Torres (digitalizado en <http://galiciana.bibliotecadegalicia.xunta.es/118n/catalogo_image nes/grupo.cmd?path=1130346>).

LOPEZ MARTINEZ-MORAS, Santiago (2007): «Aparición e florecemento da prosa medieval galega», en A. I. Boullón Agrelo, ed., Na nosa lyngoage galega: a emerxencia do galego como lingua escrita na Idade Media, Santiago de Compostela, Consello da Cultura Galega-Instituto da Lingua Galega, pp. 447-472.

LORENZO, Ramón (1988): «Normas para a edición de textos medievais galegos», en D. Kremer, ed., Actes du XVIIIe Congrès International de Linguistique et de Philologie Romanes, Université de Trèves (Trier), 1986, Tübingen, Max Niemeyer Verlag, VI, pp. 76-85.

LORENZO, Ramón (1993): «Tratado de Alveitaria», en G. Lanciani y G. Tavani, coords., Dicionário da Literatura Medieval Galega e Portuguesa, Lisboa, Caminho, p. 635 .

LoRENZO, Ramón (1995): «La Koiné gallega», en G. Holtus, M. Metzelin y C. Schmitt, eds., Lexikon der Romanistischen Linguistik (LRL), vol. II, 2 (Les différents langues romanes et leurs régions d'implantation du Moyen Âge à la Renaissance), Tübingen, Max Niemeyer Verlag, pp. 649-679. 
LORENZO, Ramón (1998): «A prosa galega medieval», en A. Ferrari, ed., Filologia classica e filologia romanza: esperienze ecdotiche a confronto. Atti del Convegno (Roma 25-27 maggio 1995), Spoleto, Centro Italiano di Studi sull'Alto Medioevo, pp. 121-136.

LoRENZO, Ramón (2000): «Prosa Medieval», en M. Brea, coord., Galicia. Literatura. Tomo XXX. A Idade Media, A Coruña, Hércules de Ediciones, pp. 365-429.

MAIA, Clarinda de Azevedo (1986): História do Galego-Português. Estado Lingüístico da Galiza e do Noroeste de Portugal desde o século XIII ao século XIV (Com referência à situação do galego moderno), Coimbra, Instituto Nacional de Investigação Científica.

MAZZINI, Innocenzo (1989): Introduzione alla terminologia medica, Bologna, Pàtron.

McVaugh, Michael R. (1997): Guigonis de Caulhiaco (Guy de Chauliac), Inventarium sive chirurgia magna, Leiden-New York-Köln, E.J. Brill, 2 vols.

Mensching, Guido (1994): La Sinonimia delos nombres delas medeçinas griegos e latynos e aranigos, Madrid, Arco/Libros.

MESSNER, Dieter (2008): «Los diccionarios bilingües español-portugués desde el principio hasta el siglo XIX», Philologia Hispalensis, 22, pp. 289-298.

Molin, Girolamo (1818): Jordani Ruffi calabriensis Hippiatria, Padova, Tipografia del Seminario (disponible en red en $<$ http://www.biusante.parisdescartes.fr/histmed/me dica/cote? extmnhny1806>).

Montero CARTElLE, Enrique (1990): «Encuentro de culturas en Salerno: Constantino el Africano», en J. Hamesse y M. Fattori, eds., Rencontres de cultures dans la Philosophie Médiévale. Traductions et traducteurs de l'Antiquité tardive au XIV siècle (Actes du Colloque international de Cassino, 15-17 juin 1989), Lovain-La-Neuve Cassino, Publications de l'Institut d’Études Médiévales, pp. 65-88.

Montero Cartelle, Enrique (2005): «La recepción de los textos médicos en la Edad Media: de Salerno a Toledo», en A. Alvar Ezquerra y J. F. González Castro, eds., Actas del XI Congreso Español de la Sociedad Española de Estudios Clásicos (Santiago de Compostela, 15-20 de septiembre de 2003), Madrid, Sociedad Española de Estudios Clásicos, III, pp. 173-206.

Montero Cartelle, Enrique y Ma Cruz Herrero Ingelmo (1998-1999): «Costantino l'Africano e il recupero dei testi greci antichi di medicina», Schola SalernitanaAnnali, 3-4, pp. 9-29.

Montinaro, Antonio (2008-2009): Cola de Jennaro, Della natura del cavallo e sua nascita (Tunisi, 1479). Edizione e spoglio lessicale di un volgarizzamento inedito da Giordano Ruffo, Università degli Studi di Roma «La Sapienza», tesi di dottorato (XXI ciclo) [inédita].

Montinaro, Antonio (2009): «Un volgarizzamento inedito da Giordano Ruffo: Cola de Jennaro, Della natura del cavallo e sua nascita (Tunisi, 1479)», en V. Ortoleva y M. R. Petringa, eds., La Veterinaria antica e medievale (testi greci, latini e romanzi). Atti del II Convegno internazionale (Catania, 3-5 ottobre 2007), Lugano, Lumières Internationales, pp. 471-530.

Montinaro, Antonio (2010): «Per la tradizione del De medicina equorum di Giordano Ruffo (con un elenco dei testimoni manoscritti)», Medioevo Letterario d'Italia. Rivista Internazionale di Filologia, Linguistica e Letteratura, 7, pp. 29-64.

Montinaro, Antonio (2015): La tradizione del De medicina equorum di Giordano Ruffo. Con un censimento dei testimoni manoscritti e a stampa, Milano, Ledizioni. 
Moule, Léon (1913): «Glossaire vétérinaire médiéval», Janus. Archives internationals pour l'histoire de la médecine et de la géographie médicale, XVIII, pp. 265-272, 363-379, 439-453, 507-535.

Niedermann, Max (1910): Proben aus der Sogenannten Mulomedicina Chironis (Buch II und III), Herausgegeben von Max Niedermann, Heildelberg, Carl Winter's.

Nieto Jimenez, Lidio y Manuel Alvar EzQuerRa (2007): Nuevo Tesoro Lexicográfico del español (s. XIV-1726), Madrid, Arco Libros, 11 vols.

$N T L L E=$ REAL ACADEMIA ESPAÑOLA, Nuevo Tesoro Lexicográfico de la Lengua Española $<\mathrm{http}$ :/www.rae.es/recursos/diccionarios/diccionarios-anteriores-1726-1992/nuevotesoro-lexicografico>.

Olrog Hedvall, Yvonne (1995): Giordano Ruffo, Lo Libro dele marescalcie dei cavalli. Cod. 78 C15 Kupferstichkabinett, Berlin. Trattato veterinario del Duecento, Stockholm, Stockholms Universitat.

PAGANO, Mario (en prensa): «Les traités de mascalcia en sicilien médiéval: aperçu critique», en A.-M. Doyen y B. Van den Abeele, eds., Chevaux, chiens, faucons. $L$ 'art vétèrinaire antique et médiéval à travers les sources écrites, archéologiques et iconographiques. Colloque international, Louvain-la-Neuve, 24-26 mars, Turnhout, Brepols.

Pensado Tome, José Luis (2004): Tratado de Albeitaria, introdución, transcrición e glosario de José Luis Pensado Tomé, revisión para a imprenta e edición en apéndice de Gerardo Pérez Barcala, Santiago de Compostela, Xunta de Galicia-Centro «Ramón Piñeiro» para a Investigación en Humanidades.

Pensado Tome, José Luis (2014): «Panorama de la historia de la lexiocografía gallega», en F. Córdoba Rodríguez, E. González Seoane y M. D. Sánchez Palomino, eds., Lexicografia de las lenguas románicas. Perspectiva histórica, Berlin-Boston, De Gruyter, pp. 203-215.

Perez Barcala, Gerardo (2004): «Apéndice: Proposta de edición», en J. L. Pensado Tomé, Tratado de Albeitaria, introdución, transcrición e glosario de José Luis Pensado Tomé, revisión para a imprenta e edición en apéndice de Gerardo Pérez Barcala, Santiago de Compostela, Xunta de Galicia-Centro «Ramón Piñeiro» para a Investigación en Humanidades, pp. 365-414.

PEREZ BARCAlA, Gerardo (2013): A tradución galega do Liber de medicina equorum de Giordano Ruffo, [A Coruña], Fundación Barrié.

PEREZ BARCALA, Gerardo (2016): «Apuntes sobre unas voces inexistentes en la traducción gallega de Giordano Ruffo (A propósito de unas recetas del De medicina equorum)», Pallas, 101, pp. 225-248.

Perez PASCUAL, José Ignacio (1992): «Algunas aportaciones de la Suma de la Flor de Cirugía al conocimiento del léxico medieval castellano», en J. A. Bartol Hernández, J. F. García Santos y J. de S. Guervós, eds., Estudios filológicos en homenaje a Eugenio de Bustos Tovar, Salamanca, Universidad de Salamanca, II, pp. 749-760.

Perona, José (2008): «Las Castigationes Plinii y el ars medicamentaria de Nebrija», Revista de Investigación Lingüística, 11, pp. 249-264.

PoUlle-DrIEUX, Yvonne (1966): «L'hippiatrie dans l'Occident latin du XIII ${ }^{\mathrm{e}}$ au XV siècle», en Y. Poulle-Drieux y J.-M. Dureau-Lapeyssonie, Médecine humaine et vétérinaire à la fin du Moyen Âge, Genève-Paris, Librairie Droz-Librairie Minard, pp. 9-172. 
Prevot, Brigitte (1989): La Marechaucie des chevaux, ou la traduction française du De medicina equorum de Jordanus Rufus. Edition critique, Lille, ANRT Université de Lille III, thèse de doctorat [inédita].

Prevot, Brigitte (1991): La science du cheval au Moyen Age. Le Traité d'hippiatrie de Jordanus Rufus, Paris, Klincksieck.

Robles GoMeZ, José María (1999): Vegecio, Medicina veterinaria, Madrid, Gredos.

RODRIGUeZ PARADA, Raquel (2014): As Encrobas, Noia, Ribadulla e Urdilde. Edición crítica, estudo léxico e onomástico de documentos notariais en galego do século $X V$, A Coruña, Deputación Provincial da Coruña.

SAlmon, Fernando y Montserrat CABRE (1998): «Fascinating Women: The Evil Eye in Medical Scholasticism», en R. French, J. Arrizabalaga, A. Cunningham y L. García-Ballester, eds., Medicine from the Black Death to the French Disease, Aldershot, Asghate, pp. 53-84.

SAnChEZ-Prieto BorJa, Pedro (1998): Cómo editar los textos medievales. Criterios para su presentación gráfica, Madrid, Arco Libros.

Santamarina, Antón (2003): Diccionario de Diccionarios. Versión 3, A Coruña, Fundación «Pedro Barrié de la Maza»-Instituto da Lingua Galega [CD-ROM] (también disponible en red en la dirección $<\mathrm{http} / /$ sli.uvigo.es/DdD/>).

SiLVeSTRE, João Paulo (2008): Bluteau e as origens da lexicografia moderna, Lisboa, Imprensa Nacional-Casa da Moeda.

StivalA, Laura (2013-2014): Un inédito trattato di mascalcia in volgare siciliano: ms. Marciano it. III, 27 (5008), cc. 23r-63v, Università degli Studi di Catania, tesi di laurea [inédita].

TABANelli, Mario (1970): Un chirurgo italiano del 1200: Bruno da Longobardo, Firenze, Leo S. Olschki Editore.

Tato Plaza, Fernando R. (1999): Libro de Notas de Álvaro Pérez, notario da terra de Rianxo e Postmarcos (1457), Santiago de Compostela, Consello da Cultura Galega.

$T I L G=$ SANTAMARINA, Antón, coord., Tesouro informatizado da lingua galega, Santiago de Compostela, Instituto da Lingua Galega, <http://ilg.usc.es/TILG/>.

$T L I O=$ Consiglio nazionale delle ricerche (CNR), Centro di studi Opera del Vocabolario Italiano (OVI), Tesoro della Lingua Italiana delle Origini, $<$ http://tlio.ovi.cnr.it/TLIO/>.

TMILG = VARELA FERREIRO, Xavier, dir., Tesouro Medieval Informatizado da Lingua Galega, Santiago de Compostela, Instituto da Lingua Galega, $<$ http.//ilg.usc.es/tmilg $>$.

Trolli, Domizia (1990): Studi su antichi trattati di veterinaria, Parma, Università degli Studi.

Urso, Rita Antonella (1900-1991): Il Libro di mascalcia di Cola de Jennaro (1479). Edizione, commento linguistico e glosario, Università degli Studi di Lecce, tesi di laurea [inédita].

VAZQUEZ DiegueZ, Ignacio (2008): «Los orígenes (tardíos) de la lexicografía bilingüe español-portugués», ELUA, 22, pp. 263-277.

VAZQUEZ DiegUeZ, Ignacio (2011a): «Quinientos años de diccionarios en portugués», Revista de Lexicografia, XVII, pp. 209-236.

VAZQUEZ DIEGUEZ, Ignacio (2011b): «Contribuição para a história da lexicografia bilingue entre as línguas espanhola e portuguesa», en T. dos Santos Verdelho y J. P. Sil- 
vestre, eds., Lexicografia bilingue. A tradição dicionarística Português-Línguas Modernas, Lisboa, Centro de Linguística da Universidade de Lisboa, pp. 82-102.

Verdelho, Telmo y João Paulo Silvestre, coords. (2007): Dicionarística Portuguesa. Inventariação e estudo do património lexicográfico, Aveiro, Universidade de Aveiro.

\section{APÉNDICES $^{78}$}

\section{LEXICOGRAFÍA GALLEGA ${ }^{79}$}

Sobreira (1790c) [= SOBREIRA SALGADO, Juan, «"Vegetables de Galicia" seguido dunhas "Retractationes" e duns "Documentos justificativos de la nomenclatura botánica gallega"» [1790], en J. L. Pensado Tomé, ed. (1974), Opúsculos lingüisticos del siglo XVIII, Vigo, Galaxia, pp. 241-267] escrofularia da yagoa. (aquatica). Herva dos lamparós.

Rodríguez (1863) [= RodRíGUEZ, Francisco Javier (1863): Diccionario gallego-castellano, ed. de Antonio de la Iglesia González, A Coruña]

Erba dos lamparós. Escrofularia.

Cuveiro (1876) [= CUVEIRo PIÑOL, Juan (1876): Diccionario gallego, Barcelona]

Herba dos lamparós. Según Rodriguez es la escrofularia, [...].

Lamparós y Lamparons. Escrófulas, y las señales que estas dejan por efecto de los tumores que se forman al obstruirse las glándulas del cuello.

RAG (1913-1928) [= REAL ACADEMIA GALEGA [1913-1928]: Diccionario gallego-castellano]

${ }^{78}$ Los tres apéndices que siguen buscan completar y apoyar la exposición realizada en el apartado 2.2.1 de este artículo en tanto que pretenden ser una muestra suficientemente representativa de la información que la lexicografía gallega, portuguesa y española ofrecen para las voces que han constituido el eje de la exposición. Al respecto de la información contenida en este inventario conviene advertir que, en caso de que alguno de los términos estudiados tenga varias acepciones (como sucede con alporca, puerca o lamparón), tan solo se ha dejado constancia de aquella(s) que los vincula con el campo médico, por mucho que nuestra aproximación se haya realizado desde una perspectiva exclusivamente filológica. Por otro lado, aunque este catálogo —en el que se prima la ordenación cronológica de los diccionarios- se pretende exhaustivo, se ha optado por incluir solo las definiciones que se ofrecen para los lemas escrófula, alporcalporca, lamparón y estruma (y las respectivas voces latinas a las que estos responden), por lo que, si bien algunas de las herramientas informáticas manejadas permitían hacer búsquedas por palabras que localizaban las voces estudiadas bajo otros lemas, no se ha estimado oportuna la inclusión de estos (salvo en casos particulares en los que la información ofrecida para esos otros vocablos mostrase relevancia de algún tipo en el desarrollo de la exposición realizada en el referido capítulo 2.2.1): así, por ejemplo, las palabras estudiadas se hallan en trabajos lexicográficos portugueses como los de Pereira (Prosodia, Thesouro) - s. v. bronchocele, cacubalum, cela, choeras, crauta, glandula, millemorbia, sevatio, caroço, trama - Fonseca (Parvum Lexicon) — s. v. cacubalum - o Bluteau (Vocabulario) s. v. adenoso, fedegosa, girasol, infusam, mesentério, ranûnculo-, Novo Diccionario —s. v. spina-ventosa-, pero estas entradas no se han recogido a fin de no extender aun más este Apéndice. Además, se han incorporado términos que forman parte de la familia léxica de cada uno de los sustantivos mencionados, sobre todo en los casos en que la definición de aquellos introduce la palabra base: así, por ejemplo, para la voz escrofularia (en gallego, portugués y castellano) se ha prescindido de aquellas definiciones que describen la planta y sus variedades, sin destacar su relación semántica con la palabra escrófula. Señalamos, en fin, que, cuando varias ediciones de un mismo diccionario ofrecen la misma (o muy próxima) definición, se recoge solo la primera en la que dicho valor semántico se registra, no mencionándose las sucesivas ediciones.

${ }^{79}$ Como ya se ha dicho, el acceso a la lexicografía gallega se ha realizado a través del soporte electrónico coordinado por Santamarina (2003), también disponible en red en la dirección $<\mathrm{http} / / /$ sli.uvigo.es/DdD/>. Las abreviaturas y referencias bibliográficas (más o menos completas) de los diccionarios se corresponden con las proporcionadas en dicho recurso. 
Alporca. s. f. med. Tumor de las glándulas que suele reventar y convertirse en llaga: escrófula de las glándulas del cuello: bocio.

Filgueira (1926) [= FILGUEIRA VALVERDE, X., et al. (1926): Vocabulario popular castelán-galego (publicado por entregas en El Pueblo Gallego)]

Estruma. v. Escrófula. Papera.

Lamparón. s. m. Escrófula.

Carré (1928-1931) [= CARRÉ Alvarellos, Leandro (1928-1931): Diccionario galego-castelán, A Cruña, Edición Lar $\left(1^{\mathrm{a}}\right.$ ed. $\left.)\right]$

Alporca. s. f. Escrófula. Tumor escrofuloso.

Estruma. s. f. Escrófula.

Estrumoso, -sa. adj. Escrofuloso.

Ibáñez (1950) [= IBÁÑEZ FERNÁNDEZ, José (1956² [1950]): Diccionario galego da rima e galegocastelán, Madrid]

Alporca. s. f. Escrófula. Lamparón.

Estruma. s. f. Escrófula.

Estrumoso, -sa. adj. Escrofuloso.

Eladio (1958-1961) [= RoDRíGUEZ GONZÁLEZ, Eladio (1958-1961): Diccionario enciclopédico gallegocastellano, Vigo, Galaxia]

Alporca. s. f. Escrófula de las glándulas del cuello, tumor de las mismas glándulas, que suele reventar y convertirse en llaga.

Escrófula. s. f. Escrófula, tumor frío originado de la hinchazón de los ganglios linfáticos, y particularmente de los del cuello.

Escrofuloso, sa. adj. Escrofuloso, que pertenece a la escrófula $\|$ adj. y s. Escrofuloso, que padece escrófulas.

Lamparós, s. m. pl. Lamparones, señales que dejan las escrófulas en las glándulas del cuello.

Franco (1972) [= Franco GRANDE, Xosé Luis $\left(1972^{2}\right.$ [1968]: Diccionario galego-castelán e vocabulario castelán-galego, Vigo, Galaxia]

Alporca. s. f. Escrófula de las glándulas del cuello, tumor de las mismas glándulas, que suele reventar y convertirse en llaga.

Estruma. s. f. Escrófula

Estrumoso, -sa. adj. Escrofuloso.

Carré (1979) [= CARRÉ Alvarellos, Leandro (1979): Diccionario galego-castelán e Vocabulario castelán-galego, A Coruña, Moret]

Alporca. s. f. Escrófula. Tumor escrofuloso.

Estruma. s. f. Escrófula.

Estrumoso, -sa. adj. Escrofuloso.

CGarcía (1985) [= GARCíA GONZÁLEZ, Constantino (1985): Glosario de voces galegas de hoxe, Santiago de Compostela, Universidade de Santiago de Compostela (Verba, anexo 27)]

Alporca. f. (Com). escrófula en el cuello.

\section{LEXICOGRAFÍA PORTUGUESA ${ }^{80}$}

${ }^{80} \mathrm{El}$ parcial acceso a los vocabularios portugueses se ha realizado a partir del Corpus Lexicográfico do Portugués $(C L P) —<\mathrm{http}: / /$ clp.dlc.ua.pt $>$ - y la puntual consulta de algunos que, no estando incluidos en esa herramienta informática, se han examinado por otras vías. Los diccionarios revisados a partir del soporte electrónico citado se destacarán con la marca $(*)$ y se citarán con la abreviatura que los identifica en ese recurso, creando una propia para aquellos a los que se ha accedido de otros modos. 
Cardoso, Dict. iuventuti studiosae [= CARDoso, Jerónimo (1562): Hieronymi Cardosi Dictionarium Iuventuti studiosae admodum frugiferum, Coimbra, João Álvares (*)]

Struma(ae). A Alporca.

Strumosus(a. um). Cousa doente de alporcas.

Cardoso, Dict. ex lusitanico in latinum [= CARDOSO, Jerónimo (1562-1563): Hieronymi Cardosi Lamacensis Dictionarium ex lusitanico in latinum sermonem, Coimbra, João Álvares (*)]

Alporca. Struma(ae)

Cardoso, Dict. Latinolusitanicum [= CARDOSO, Jerónimo (1569-1570): Dictionarium latinolusitanicum $\&$ vice versa lusitanicolatinum cum adagiorum fere omnium iuxta seriem alphabeticam perutili expositione, Coimbra, João de Barreira $(*)]$

Scropha(ae). A porca velha. ou parida.

Scrophula(ae). A alporca.

Scruphula(ae). Alporca.

Struma(ae). Alporca. ou trama.

Barbosa, Dictionarium [= BARBosA, Agostinho (1611): Dictionarium lusitanico latinum, Bracharae, typis, \& expensis Fructuosi Laurentij de Basto $(*)]$

Alporcas. Struma, ae, Cic. pro Sextio. Scrofula, ae vel Scrophula, ae, pen. corr. Tonsillae, arum, Plin. lib. 11 cap. 37. Adenes, pen. corr. Aegineta lib. 3. Alporquenta cousa. Strumosus, a, um, adiectivum. Colum. lib. 7. Cap. 10. Alporcar cardos. Defodere carduos.

Pereira, Prosodia [= PEREIRA, Bento (1697 [1634]): Prosodia in vocabularium bilingüe, Latinum, et Lusitanum.... Septima editio auctior, et locupletior ab Academia Eborensi, Evora, Tipografia da Academia $(*)^{81}$ ]

Scrofa, ae, f. g. Porca parida, ou porca velha. 1. 1. Juv. 12.

Scrofula, ae, f. g. dim. A porca pequena; in pl. as alporeas [sic], parotidas, boubas, \& c. 1. 1. 2. b. Cels.

Struma, ae, f. g. O inchaço, alporcas, parotida, apostema, boubas, \& c. item a infamia, deshonra, homem deshonesto, \& c. Macer. de Borag. Trita solet veteres compescere cum sale strumas.

Strumaticus. Strumicus, a, um. Cousa doente de alporcas, parotida, \& c.

Strumosus, a, um. Cousa alporquenta, doente de alporcas, boubas, parotida, \& c. Juv. 10. Strumosum, atque utero pariter, gibboque tumentem.

Pereira, Thesouro [= PEREIRA, Bento (1697 [1647]): Thesouro da lingua portugueza, Évora, Tipografia da Academia $(*)]$

Alporcas. Struma, ae. Scrofula, ae. Tonsillae, arum.

Franco, Indiculo [= FrANCO, António (1716): Indiculo Universal. Contem distinctos em suas classes os nomes de quazi todas as cousas que ha no mundo, \& os nomes de todas as Artes e Sciencias, Évora, Universidade $(*)$ ]

Alporcas. Strumae, arum.

Doente de Alporcas. Strumosus.

Porca parideira. Scrofa, ae.

Bluteau, Vocabulario [= BLUTEAU, Rafael (1712-1728): Vocabulario portuguez e latino, Coimbra, Collegio das Artes da Companhia de Jesu $(*)]$

${ }^{81}$ En la edición de Vlissypone, Craesbeeck, 1653 (disponible en $<$ http://books.google.es/>), como equivalente de las voces latinas scrofula, ae y struma, ae se da «A alporca» $\mathrm{y}$ «A alporca. Laparon» respectivamente. Esa edición incluye, asimismo, las entradas «Scrofularia, ae. Erva pera curar alporcas» y «Strumea, ae. Erua pera curar alporcas». 
Alporca. Enfermidade assim chamada, porque he ordinaria nos porcos. Saõ tumores schirrosos de humas pequenas glandulas, encerradas em membrana particular. Muitas veses occupa o tumor todas as glandulas em geral, particularmente as da garganta, pescoço, sobacos, verilhas, \& peitos, \& algumas vezes as do mezenterio. As que daõ na garganta, se chamaõ Bronchocele. Differem dos mais tumores glandulosos, em serem mais numerosos, \& lançarem raizes mais profundas, que saõ causados de humor pituitoso, $\&$ crù, que se parece com gesso, $\&$ que metido nos poros, $\&$ vasos capilares das partes, engendra humas obstrucçoens, \& he causa, de que as ditas partes se vaõ pouco a pouco inchando, a modo de esponja chea de vescosidades, que successivamente se endurecem, por meio do acido dominante, $\&$ tendente a coagulaçaõ. As alporcas verdadeiras, \& legitimas saõ brancas, \& sem dor, as falsas, ou bastardas, saõ lividas, picantes, \& dolorosas. A fama do prodigioso contacto dos Reys de França na cura deste achaque esta fundada, em que (segundo escreve Mezeray \& outros Historiadores do ditto Reyno.) a Clodoveo, primeiro Rey Christaõ dos Francezes, depois de bautizado, trouxera hum Anjo a Sagrada Ambula, com cujo oleo se ungem os Reys de França, \& juntamente concedera o Ceo ao ditto Princepe o Dom de curar esta enfermidade, da qual fizera em Aniceto seu valido a primeira experiencia; o qual singularissimo privilegio se foi communicando aos seus successores, com as demonstraçoens, $\&$ evidencias das curas, que entre outras naçoens a que atè agora foi menos affecta a França, publicamente o confessa, naõ de cura instantanea, mas successiva, secandose insensivelmente as alporcas. O que tambem se confirma com o continuado concurso dos enfermos deste achaque, a que a cura dos seus paysanos, \& vesinhos obriga a hir buscar da sua patria a França a suspirada saude. Struma, ae Fem. Cic. Cels. \& Plinio as vezes dizem struma no singular, \& outras vezes strumae no plur. segundo certo Etymologista, chamaoõlhe os latinos Strumae â struendo, quia structum assurgunt, quippe tumor glandularum ex impacto humore crasso.

Alporquento. O que tem alporcas. Strumosus, a, um colum. Juven.

Antistrumâtico. Termo de Medico. Bom contra as Alporcas. Em Latim chamãose Strumae. Quod contra strumas prodest. \{A quem curei de Alporcas com as minhas pirolas Antistrumaticas. Curvo, Observaç. Medicas, 53$\}$ Na pag. 485. chamalhe Pirolas estrumosas.

Escorfulária. Erva. Derivase do Latim Scrophulae, Alporcas, porque dizem que he boa para este mal, ou porque a raiz desta erva, nas suas desigualdades representa humas vegetativas alporcas. [...]

Escrófula. Alporca. Vid. no seu lugar. \{As Escrofulas pequenas, molles, \& de pouco tempo se pode facilmente resolver. Cirurg. de Ferreira, 128.\}

Escrófulas. He o nome Latino de Alporcas. Vid. no seu lugar. \{Escrofulas, Lobinhos, Bocio. Recopil. de Cirurg. 120\}

Estrumoso. Termo de Medico. Derivase do Latim Strumae, que quer dizer Alporcas. Pilulas estrumosas, saõ as que curaõ as alporcas. Vid. Antistrumatico.

Orgevaõ. Herva. Chamã olhe outros Orjavaõ, \& outros Urgebão, [...] \{(A raiz do orgevão trazida ao pescoço, \& renovada cada oyto dias, cura as alporcas por virtude occulta. Curvo, Observ. Medic. pag. 58)\}

Porca. [...] Porca que pario muitas vezes, ou que se guarda para a geraçaõ. Scrofa, ae. Fem. Varro

Bluteau, Diccionario Castellano y Portuguez [= BlutEAU, Rafael (1721): Diccionario Castellano y Portuguez para facilitar a los castellanos el uso del Vocabulario Portuguez, y Latino, Lisboa Occidental, Officina de Pascoal da Silva $\left.\left(^{*}\right)\right]$

Lamparones. Alporcas.

Puerca. Alporca.

Bluteau, Tabla [= BluteAu, Rafael (1721): Tabla de Palabras Portuguezas, remotas de la Lengua Castellana, Lisboa Occidental, Officina de Pascoal da Silva $(*)$ ]

Alporcas. Lamparones.

Escrofulas. Lamparones. 
Feijó, Orthographia [= FEIJÓ, João de Morais Madureira (1734): Orthographia, ou Arte de escrever, e pronunciar com acerto a Lingua Portugueza, Lisboa Occidental, Officina de Miguel Rodrigues $(*)]$

Escrófula. o mesmo que alpórca.

Folqman, Diccionario [= FolQman, Carlos (1755): Diccionario Portuguez, e Latino, Lisboa, Officina de Miguel Menescal da Costa $(*)]$

Alporcas, pl. f. Struma, ae, f. ou no pl. Strumae, arum.

Fonseca, Parvum Lexicon [= FonseCA, Pedro José da (1798 [1762]): Parvum lexicum latinum lusitana interpretatione adjecta, Olisipone, Typographia Regia $(*)]$

Scrofa, ae, f. Varr. Porca velha, animal.

Struma, ae, f. Cic. Alporca, parotida, beuba.

Strumosus, a, um, Juv. Alporquento, doente de alporcas.

Morais, Diccionario [= MoraIs Silva, Antônio de (1798): Diccionario da lingua portugueza composto pelo padre D. Rafael Bluteau, reformado e accrescentado por Antonio de Moraes Silva natural do Rio de Janeiro, Lisboa, Officina de Simão Thaddeo Ferreira [<http://www.brasiliana.usp.br/pt-br/dicionario/edicao/2>]]

Alporca, s. f. tumor scirroso, que occupa alguma, ou todas as glandulas do pescoço, e outras, o qual se rompe em chaga: usa-se em geral no pl. v. g. tem alporcas.

Escrófula, s. f. Alporca, doença.

Escrofuloso, adj. que tem alporcas.

Morais, Grande dicionário [= MoRAIS SiLVA, Antônio de (1949-1959 ${ }^{10}$ [1798]): Grande dicionário da lingua portuguesa, Lisboa, Confluência]

Alporca, s. $f$. Nome vulgar das escrófulas, sobretudo no pescoço: «Deram-lhe alporcas, e tinham-lhe o pescoço tão afeado de lândoas... que se não atrevia aparecer em público», Fr. Luís de Sousa, História de S. Domingos, II, cap. 26, 201, ed. de 1767; «... tinha uma grande celebridade adquirida na cura... das lombrigas... em alporcas era infalível», Camilo, Eusébio Macário, cap. 3, 43, ed. de 1897.

Alporcado, adj. e p.p. (de alporcar). Que tem alporcas. [...]

Alporquento, adj. (de alporca). Doente de alporcas; escrofuloso: «Depois de sangrado o alporquento algumas vezes», Curvo Semedo, Atalaya da Vida, 14.

Antiestrumático, adj. Med. Que combate as escrófulas.

Escrófula, $s$. f. (do lat. scrofulae). Med. Doença que consiste num engorgitamento das glándulas linfáticas e que se manifesta por pequenos tumores ovulares que podem ficar por algum tempo inertes ou estacionários e mesmo desfazer-se sendo tratados, ou, não o sendo, inflamar-se e originar úlceras fistulas. $\| \mathrm{O}$ tumor escrofuloso.

Escrofulária, s.f. (de escrófula). Bot. Planta medicinal, que se receitava contra escrófulas (Scrofularia aquatica).

Escrofulismo, s. m. Pat. Estado do doente atacado de escrófulas; o mesmo que escrofulose.

Escrofulose, $s$. $f$. Doença dos que sofrem escrófulas.

Escrofuloso ${ }^{1}$, adj. (de escrófula). Relativo a escrófulas. \| Que padece escrófulas: «Sem vontade de viver, escrofuloso e porco, arrastava-se pelas calçadas», Aloísio de Azevedo, Girândola de Amores, cap. $14,168$.

Escrofuloso $^{2}$, s. m. (de escrófula). Aquele que tem escrófulas.

Estruma $^{1}$, s. f. (do lat. struma). Escrófula. \|| Bocio.

Estrumose, s. f. Pat. O mesmo que escrofulose.

Estrumosidade, s. $f$. $\left(\right.$ de estrumoso $\left.{ }^{2}\right)$. Med. Estado de estrumoso ${ }^{2}$.

Estrumoso $^{2}$, adj. e $s$. $m$. (de estruma). Que padece estruma: «Criatura profundamente tarada, com a pesada herança dos estrumosos de Medina Sidónia, irmã dum tuberculoso», Júlio Dantas, $\mathrm{Ou}$ tros Tempos, 95. 

(bócio).

Estrumite, s. f. (do lat. struma). Pat. Inflamação da glândula tiroideia já com lesões tumorais

Novo Diccionario [= Novo Diccionario da Lingua Portugueza, Lisboa, Typografia Rollandiana, 1817] plural.

Alporca. s. f. Tumor scirroso das glandulas, que vem a romper-se em chaga. Usa-se em geral no

Alporquento, adj. Que tem alporcas.

Antistrumatico, adj. Contra as estrumas, ou alporcas.

Escrofula, s. f. O mesmo que alporca, doença de humores frios.

Escrofularia, s. f. Herva medicinal contra as escrofulas.

Escrofuloso, adj. Doente de escrofulas. Concernente a escrofulas.

Estrumoso, adj. Na Medicina diz-se dos remedios que curaõ alporcas.

Fonseca, Novo diccionario [= FONSECA, José da (1843 [1833]): Novo diccionario da lingua portugueza seguido de um diccionario completo dos synonymos portugueses, Paris, Aillaud $[<\mathrm{http} / /$ books.google.es/books?id=yvdDAAAAcAAJ $>$ ]]

Alporca, s. f. tumor scirroso das glandulas, (rompe-se em chaga).

Alporcado, p. pas. que tem alporcas.

Alporquento, adj. doente d'alporcas.

Escrofula ou Scrofula, s. f. alporca (doença).

Escrofuloso ou scrofuloso, adj. alporquento.

Constancio, Novo Diccionario critico [= Constancio, Francisco Solano (1852 ${ }^{4}$ [1836]): Novo Diccionario critico e etymologico da Lingua Portugueza, Paris, Angelo Francisco Carneiro Filho]

Alporca, $s$. $f$. (do Lat. porca, com o artigo Arab. al; [...]. Os tumores escrofulosos sobresahem no pescoço e outras partes. Em Lat. struma de struor, $i$, elevar-se, formar eminencia), mais us. no pl. escrofulas, tumores das glandulas lymphaticas, que ordinariamente vem ao pescoço, e são indolentes; $[\ldots]$.

Alporquento, a, adj. (alporca, e des. ento, mudado o $c$ em qu, para não soar cento), achacado, doente de alporcas, escrofuloso. $[\ldots]$

Antistrumatico, a, adj. (anti, e struma, Lat. alporcas), t. med., contra as escrofulas, ou alporcas.

Escrofularia, s. f. (Lat. scrophularia), herva medicinal boa contra as escrofulas.

Escrofulas, s. f. pl. (Lat. scrofula, dim. de scrofa, porca; it. alporcas, doença; porque as porcas são sujeitas ás alporcas); t. de med., alporcas, tumores lymphaticos glandulares.

Escrofuloso, a, adj. (des. oso), que tem escrofulas ou alporcas.

Estrumas. $V$. Alporcas, Escrofulas.

Estrumoso, a, adj. (des. oso), escrofuloso; it. util contras as alporcas, v.g. pilulas estrumosas, contra as escrofulas.

Faria, Novo Diccionario [= FARIA, Eduardo (1850² [1849]): Novo Diccionario da Lingua Portugueza. O mais exacto e mais completo de todos os diccionarios ate hoje publicados, Lisboa, Typographia Lisbonense de José Carlos d'Aguiar Viana]

Alpórca, $s$. $f$. (Lat. porca, com o artigo Arab. al, [...]. Os tumores escrofulosos que sobresaem no pescoço e outras partes. Em Lat. struma de struor, $i$, formar eminencia, elevar-se) (med.) tumor duro, scirroso, umas vezes com dôr, outras sem ellas, que se fórma pouco a pouco nas glandulas conglobadas do pescoço, garganta, etc.

Alporcádo, a, [...]; adj. que tem a enfermidade das alporcas.

Alporquento, a, adj. doente de alporcas, ou que tem alporcas principalmente no pescoço.

Antistrumático, a, adj. (anti, e struma, Lat., alporcas.) (med.) contrario ás alporcas, ou util para cura-las.

Escrofularia, s. f. (Lat. scrofularia, ae; scrophularia, ae) (bot.) genero de plantas da didynamia angioespermia de Linneo, familia das personadas de Jussieu. A - nodosa (das boticas, herva contra 
as escrofulas: [...]); clymenon, $i$, de Linneo (herva saboeria), foi recommendada como tonica, resolutiva, e anstiscrofulosa. [...].

Escrófulas, s. f. pl. (Lat. scrofula, ae, dim. de scrofa, ae, porca; alporcas, doença; porque as porcas são sujeitas ás alporcas) alporcas, tumores lymphaticos glandulares, consistem na degeneração das glandulas lymphaticas superficiaes, particularmente do pescoço, com alteração dos fluidos que os penetram [...].

Escrofulôso, a, adj. (Lat. scrofulosus, a, um) que é affectado, que tem escrofulas ou alporcas; que tem relação com essa molestia.

Estrúmas. V. Alporcas, Escrofulas.

Estrumoso, a, adj. escrofuloso, util contra as alporcas. Pilulas -, contra as escrofulas.

Roquete, Diccionario [= RoQuETE, José Inácio (1856 [1848]): Diccionario da Lingua Portugueza de José da Fonseca, feito inteiramente de novo e consideravelmente augmentado, Paris-Lisboa, Guillard-Aillaud, sammlungen.de/resolve/display/bsb10588334.html $>$ ]]

$[<\mathrm{http}: / /$ reader.digitale-

Alporca, s. f. tumor scirroso das glandulas (rompe-se em chaga); [...].

Alporcado, a, adj. que tem alporcas. [...]

Alporquento, a, adj. doente d'alporcas.

Antistrumatico, a, adj., contra as estrumas ou alporcas.

Escrofula, $s . f$. alporca (doença).

Escrofuloso, a, adj. alporquento.

Estrumas, V. Escrofulas.

Estrumoso, a, adj. doente de alporcas. Pirolas - as, que curão alporcas.

Mascarenhas Valdez, Diccionario español-portugués [= MASCARENHAS VALDEZ, Manuel do Canto e Castro (1864-1866): Diccionario español-portugués: el primero que se ha publicado con las voces, frases, refranes..., Lisboa, Imprenta Nacional]

Escrófula. $f$. (med.) Escrofula, alporcas; enfermidade caracterisada por uma degeneração dos ganglios lymphaticos superficiaes, particularmente dos do pescoço, com alteração dos fluidos que os atravessam. Scrofulae.

Escrofuloso, sa adj. Escrofuloso; diz-se de quem é affectado de escrofulas, e do que tem relação com esta molestia. Ad scrofulas pertinens, vel scrofulis laborans.

Estruma $m$ (med.) Estruma; synonymo de escrofula, segundo alguns medicos, e segundo outros, tumor da glandula thyroidea, que póde apresentar-se em todas as idades mas sem chegar á suppuração.

Estrumosidad $f($ med.) Estrumosidade; reunião de muitos tumores em diversas partes do corpo, e particularmente no pescoço das pessoas que têem uma constituição escrofulosa ou que padecem de escrofulas.

Estrumoso, sa adj. (med.) Estrumoso. V. Escrofuloso.

Lamparon. Alporcas, escrophulas; tumores que nascem no pescoço. Scrofulae, arum.

Lamparonoso, adj. (med.) V. Escrofuloso.

Coelho, Diccionario Manual [= Coelho, Francisco Adolpho (1890): Diccionario Manual Etymologico de Lingua Portugueza, Lisboa, P. Plantier Editor]

Alporca, s. $f$. Nome vulgar das escrophulas.

Alporcado, adj. Que tem alporcas.

Alporquento, adj. Que padece de alporcas.

Escrofula, s. f. T. med. Doença que consiste no engorgitamento com ou sem tuberculisação, dos ganglios lymphaticos superficiaes e particularmente os do pescoço, e na alteração dos fluidos que elles conteem (Lat. scrofulae).

Escrofuloso, adj. Que tem escrofulas (Escrofula, suf. oso).

Estruma, $s$. $f$. Escrofula (Lat. struma).

Estrumoso, adj. Enfermo de estrumas (Estruma, suf. oso). 
Moraes, Diccionario da Lingua [= MoraEs Silva, Antonio de $\left(1877^{7}\right)$ : Diccionario da Lingua Portuguesa, Lisboa, Typographia de Joaquim Germano de Souza Neves]

Alpórca, s. f. Escrophulas. Tumor scirroso, que occupa alguma, ou todas as glandulas do pescoço, e outros, o qual se rompe em chaga: usa-se em geral no pl. Vieir. 9. 185. «a garganta carcomida de alporcas».

Alporcado [...] adj. que tem alporcas.

Alporquènto, a, adj. Doente de alporcas. Curv. Atal. 14

Antistrumático, a, adj. (do pref. anti e do Lat. struma, alporca) t. med. Diz-se dos remedios contra as escrofulas, ou alporcas. Curv. Atal. $13 \S$ it. s. m.

Escrófula, s. f. (do Lat. scrofulae, arum) Alporca; doença. pl. Escrofulas.

Escrofulòso, ósa, adj. Que tem alporcas. § Usa-se subst.

Estrúmas, s. f. (do Lat. strumae) t. med. p. us. Escrofulas, alporcas.

Estrumòso, ósa, adj. (do Lat. strumosus) t. med. Doente de alporcas. § Pirolas estrumosas; que curam alporcas.

Chernoviz, Diccionario de medicina popular [= CHERnOviz, Pedro Luiz Napoleão (1890): Diccionario de medicina popular e das sciencias accesorias, Paris, A. Roger \& F. Chernoviz [<http://www.brasiliana.usp.br/bbd/handle/1918/00756310>]]

Alporcas. Veja-se Escrophulas.

Escrophulas. Molestia [...] cujos principaes caracteres são engurgitamento das glandulas lymphaticas e ulcerações da pelle de um aspecto particular. As escrophulas chamam-se vulgarmente alporcas. [...]

Silva Bastos, Diccionario etymologico [= Silva Bastos, José Timoteo da (1912): Diccionario etymologico, prosodico e orthographico da lingua portugueza, Lisboa, Parceria Antonio Maria Perei$\mathrm{ra}$

Alporca, $s . f$. designação vulgar das escrófulas (mas us. n'este sentido no plural)

Alporquento, adj. (pop.) que padece de escrófulas. (De alporca e ento)

Escrófula, $s$. $f$. engorgitamento dos ganglios lymphaticos com formação de tumores ovulares, etc. (Do lat. scrofulae)

Escrofulose, s.f. doença dos que soffrem de escrofulas. (De escrófula) fula)

Escrofuloso, adj. que soffre de escrofulas; - , s. m. (pop.) o mesmo que escrofulose. (De escro-

Estruma, s.f. (pop.) escrófula; bocio. (Do lat. struma)

Estrumas, s. f. pl. escrófulas. Esta pal. é mais us. no $p l$.

Estrumoso, adj. que padece estrumas. (Do lat. strumosus)

Machado, DELP [= MACHADO, José Pedro (1973³ [1952]: Dicionário Etimológico da Lingua Portugue$s a$, Lisboa, Livros Horizonte]

Alporca s. Escrófula. De al + porca, pois trata-se de decalque do lat. scrofula, «porquinha», diminutivo de scrofa, «porca». Séc. XV: «...e esta monja... era doente de Alporcas em tal maneira que a não julgauão senão aa morte...», em Reis ${ }^{5}$, p. 244, ed. de 1945.

Escrófula, s. Do lat. tardio scrōfǔla, mais vulgar no pl., «escrófulas» (em Vegecio, Mulomedicina, III, 23); o voc. lat. provém de scrōfa, «porca», termo técnico da língua rústica e dialectal, como indica o -f- intervocálico [...]; quanto ao sentido tomado pelo voc. scrōfǔla, pode tratar-se de imitação do gr. choirádes, se não se trata de mais um vestigio da analogia com os tumores ganglionares da porca; [...]. Em 1813, Morais $^{2}$.

Escrofulária, s. De escrófula. Em 1813, Morais $^{2}$.

Escrofuloso, adj. De escrófula. Em 1813, Morais $^{2}$.

Estruma, s. Do fr. strume, este do lat. strūma, «escrófulas». Em 1890, Morais ${ }^{8}$.

Cunha, Nova Fronteira [= CunHA, Antônio Geraldo da $1986^{2}$ [1982]: Dicionário Etimológico Nova Fronteira da Lingua Portuguesa, Rio de Janeiro, Editora Nova Fronteira] 
alporca $s f$. 'escrófula' XV. De porca', provavelmente porque este animal é muito sujeito a essa doença. [cf. porcA ${ }^{1} s f$. 'a fémea do porco' XIII]

escrófula $s f$. '(Patol.) designação impreciosa de estado constitucional, que se observa nos jovens, caracterizado por falta de resistência', 1813. Do lat. scro $₫$ fulae-arum. \| escrofulÁRIA 1813. Do lat. med. scrofularia $\|$ escrofuloso 1813.

estruma $s f$. 'escrófula, tumor ganglionar de natureza tuberculosa' 1844. Do lat. strūma-ae.

Academia Ciências, Dicionário [= ACADEMIA DAS CIÊNCIAS DE LISBOA (2001): Dicionário da Lingua Portuguesa Contemporânea, Lisboa, Academia das Ciências de Lisboa e Editorial Verbo]

escrófula. $s$. $f$. (Do lat. scrofúlae 'papeira'). Med. 1. Doença que consiste num ingurgitamento dos gânglios linfáticos, quase sempre de natureza tuberculosa, e que se manifesta pela formaça(Do de pequenos tumores ovulares que podem originar úlceras fistulosas . 2. Cada um desses tumores. escrofulária. s. f. (De escrófula + suf. -ária). Bot. Planta herbácea da família das escrofulariáceas (Scrophularia aquatica, L.), [...], que era receitada para tratamento das escrófulas. escrofulose. s. $f$. (De escrófula + suf. -ose). Med. Ingurgitamento dos gânglios linfáticos de natureza tuberculosa que se manifesta pela formação de pequenos tumores ovulares.

escrofuloso $^{1}$, a. adj. (De escrófula + suf. -oso). 1. Que é relativo a escrófula. Tumor escrofuloso. 2. Que tem escrófulas. [...] $[\ldots]$ escrofuloso $^{2}$, a. $s$. (De escrófula + suf. -oso). Pessoa atingida pela escrófula, que tem escrófulas.

Houaiss, Dicionário [= HouAIss, Antônio (2001): Dicionário Houaiss da lingua portuguesa, Rio de Janeiro, Editora Objetiva]

alporca. s.f. (sXV cf. IVPM supl). [...] 3. infect infirm. m.q. tuberculose linfática. 4. med. m.q. escrófula ('intumescência') etim (...) para a acp. 3: al- + lat. porca,ae 'porca', pois, segundo se cria no passado, o porco era muito sujeito a esta moléstia; $c f$. scrōfa, ae 'porca' e scrofūlae,arum 'escrófula (enfermidade)'.

alporcado adj. [...] 2. med que apresenta alporcas ('escrófulas') [...].

alporquento adj.s.m. infrm. m.q. escrofuloso etim. alporca + -ento.

escrófula s.f. (1670 cf. AFLuz) 1. infect m.q. tuberculose linfática 2. med intumescência dos gânglios do pescoço causada por esta doença; alporca, estruma etim do lat. scrofūlae,arum 'escrófulas (enfermidade)', dim. de scrōfa, ae 'porca'; parece que a relação da enfermidade com o nome-base se deve ao fato de os porcos terem sido, com freqüência, sujeitos a esta moléstia; cp. etim. de alporca; ver escroful(o)-; f.hist. 1670 escrofulas, 1813 escrófula, 1858, scrófula.

escrofulária s.f. (a1712 cf. RB) angios design. comum às ervas e arbustos do gên. Scrophularia, da fam. das escrofulariáceas [...]. etim lat.cien. gên. Scrophularia (1737), prov. calcado numa f. do lat.medv. scrofularia; parece que a motivação da escolha do nome para a planta advém da similitude dos nódulos da raiz com os gânglios inchados, provocados pela enfermidade (escrófula) e tb. da crença (na medicina antiga) de que a erva poderia servir de remédio contra a moléstia; ver escroful $(0)$-.

escroful(o)- el.comp. antepositivo, do lat. scrofūlae,arum, 'escrófulas (enfermidade)', dim. de scrofa 'porca'; ocorre em voc., em geral da terminologia médica, alguns já de orign. lat., como escrófula(s), escrofulária e em cultismos do sXIX em diante: escrofulacrina, escrofulariácea, escrofulariáceo, escrofularina, escrofularínea, escrofularíneo, escrofulizar, escrofuloderme, escrofulofina, escrofuloma, escrofulose, escrofulose, escrofuloso, escrofulótico, escrofulotuberculose, escrofulotuberculoso.

estruma s.f. (1844 cf. MS5) 1 endocr m.q. bócio 2 med m.q escrófula 3. med. qualquer tumefação, esp. ganglionar 4 infect obsl. m.q. tuberculose linfática etim lat. strūma,ae 'alporca, parótida, escrófula'.

estrumoso adj. (1713 cf. RB) med que tem estrumas; alporquento, escrofuloso etim. estruma + oso. 
estrum(i)- el.comp. antepositivo, do lat. strūma,ae 'escrófula, bócio'; ocorre já em voc. orign. latinos, como estruma e estrumoso, já em cultismos da nomenclatura médica, do sXIX em diante: estrumectomia, estrumipriva, estrumiprivo, estrumite, estrumose, estrumosidade.

\section{LEXICOGRAFÍA ESPAÑOLA ${ }^{82}$}

Voc. Gen. s. XIV [= ANÓNimo, Glosarios latino-españoles de la Edad Media, editados por Américo Castro, Madrid, CSIC, 1936] scropha [-ofa], puerca (P134).

Nebrija 1492 [= NEBRIJA, Elio Antonio de (1492): Lexicon hoc est dictionarium ex sermone latino in hispaniensem, Salamanca, s. i.] scropha, ae, por la puerca parida. scrophula, ae, por la puerca, dolencia.

Oriola Dict 1493 [= NeBRIJA, Elio Antonio de (1493): Introductiones latinae, Burgos, Federicum Alamanum] scropha, puerca.

Nebrija 1495? [= NEBRIJA, Elio Antonio de (¿1495?): Vocabulario español-latino, Salamanca, s. i., s. a.] lamparones. scrophula, ae.

puercas como lamparones, scrofulae, arum. puerca grande e parida, scrofa, ae.

Alcalá 1505 [= AlCALÁ, Fray Pedro de (1505): Vocabulista arávigo en letra castellana, Granada, Juan Varela]

lamparones. khanzira, khanizir.

puerca grande parida, khanzíra mavdóâa, khanázir mavdoâain.

puercas como lamparones, khanzira, khanǐzir.

Nebrija 1516 [= NEBRIJA, Elio Antonio de (1516): Vocabulario de romance en latín hecho por el doctíssimo maestro Antonio de Nebrissa nuevamente corregido y augmentado más de diez mill vocablos de los antes solía tener, Sevilla, Juan Varela de Salamanca]

Lamparones. Scrophula, ae, choeras, dis.

Puercas como lamparones, scrofulae, arum.

Nebrija 1518 (= NeBriJA, Elio Antonio de (1518): Dioscórides, De medicinali materia [...] Ionanne Ruelio Suessionensi interprete, Alcalá de Henares, Arnao Guillén de Brocar, 1518]

choeras, adis, morbus qui latine struma siue scropha, hispane puercas.

scrofa, ae, siue choeras, adis, latine struma, hispane puerca o lamparón. struma latine, graece vocantur choeras, adis, hispane puerca o lamparón.

Nebrija 1520 [= NeBriJA, Elio Antonio de (1520): Dictionarium Aelii Antonii Nebrissensis per eundem recognitum atque exactissime correctum. In quo multa ex superiori editione depranata emendauit, Alcalá de Henares, Arnao Guillén de Brocar] lamparones, scrophula, $e$ [añad. choeras, adis].

Ulloa Cel. 1553 [= UlloA, Alfonso de (1553): Tragicomedia de Calisto y Melibea [de Fernando de Rojas], Venecia, Gabriel Giolito de Ferrara] puerca grande y parida, per la scropha.

${ }^{82}$ Los vocabularios del castellano se han consultado a partir del Nuevo Tesoro Lexicográfico del español (s. XIV-1726) de Nieto Jiménez y Alvar Ezquerra (2007) y del Nuevo Tesoro Lexicográfico de la Lengua Española, que, accesible en la página de la Real Academia Española $(<\mathrm{http} / / / \mathrm{www}$.rae.es/recursos/ diccionarios/diccionarios-anteriores-1726-1992/nuevo-tesoro-lexicografico $>$ ), abarca un período cronológico mucho más amplio que aquel otro. Los datos bibliográficos de los diccionarios se ofrecen a partir de dichos recursos, de los que proceden también las abreviaturas con las que en ellas se idenfican. 
Junius 1567 [= JUNIUS, Hadrianus (1567): Nomenclator omnivm rervm propria nomina variis lingvis explicata indicans, Amberes, Cristóbal Plantino]

scropha $[\ldots]$, puerca parida.

struma $[\ldots]$, choeras $[\ldots]$, puerca o lamparón.

Casas 1570 [= CASAS, Cristóbal de las (1570): Vocabulario de las dos lenguas toscana y castellana, Sevilla, Francisco de Aguilar y Alonso Escribano] lamparones. scroffole, scrouole.

Percivale 1591 [= Percivale, Richard (1591): Bibliotheca Hispanica. Containing a Grammar with a Dictionarie in Spanish, English, and Latine, gathered out of diuers good Authors: very profi-table for the studious of the Spanish toong, Londres, Iohn Iackson, for Richard Watkins] lamparones, the kings euill; scrophula.

Decimator 1596 [= DECIMATOR, Heinrich (1596): Sylvae vocabulorum et phrasivm sive nomenclator [...], Leipzig, Michael Latzenberger] scrofa $[\ldots]$, puerca parida. struma $[\ldots]$, puerca, o lamparón.

Minsheu 1599 [= MinSHEU, John (1599): A Dictionaire in Spanish and English, first published into the English tongue by Ric. Periuale [...] Hereunto for the further profite and pleasure of the learner or delighted this tongue, is annexed an ample English Dictionaire [...], Londres, Edm. Bollifant] lamparones or puercas, Kernels, a swelling in the necke or armepits, the kings euill. puercas or lamparones, kernels; swelling in the armepits or necke.

Hornkens 1599 [= HoRNKENS, Henricus (1599): Recveil de dictionaires françoys, espaignolz et latins, Bruselas, Rutger Velpius]

lamparones, pesuña, escrouelles; struma. puerca, lechona parida, scroffe, ou scrophe.

Virid. s. XVII [= ANÓNIMO, Viridarium linguae latinae, manuscrito 17884 de la Biblioteca Nacional de España, Madrid] lamparones, strumae, arum, chaerades, um. puerca parida, scrofa, ae.

Bravo 1601 [= BRAVO, Bartolomé (1601): Thesavrus verborum ac phrasivm ad orationem ex hispana latinam efficiendam et ornandam plurimis locis [...], Zaragoza, Miguel Fortunio Sánchez] lamparones, chaerades, um.

Rosal 1601 [= RosAL, Francisco del (1601): Origen y etimología de todos los vocablos originales de la lengua castellana, manuscrito 6929-T.127 de la Biblioteca Nacional de España, Madrid]

Puerca de tierra, y enfermedad. B. puerco.

Puerco, de porco latino, y éste de las porcas que hacen con el hocico; y así aporcar, hacer aquellas porcas, que son montoncillos de tierra cavada, y por la semejanza de éstas se llaman puercas unas hinchazones, como lamparones o flemones, enfermedad.

Palet 1604 [= PALET, Ioan (1604): Diccionario muy copioso de la lengua española y francesa [...]. Dictionaire tres ample de la langue espagnole et françoise, París, Matthieu Guillemot] lamparones, les escrouëlles. puerca, escroüelle.

Fontecha 1606 [= ALONSO Y DE LOS RUYZES DE FONTECHA, Juan (1606): Diez privilegios para mugeres preñadas [...], Alcalá de Henares, Luis Martínez Grande] cheras, estruma, lamparón.

cirades, los lamparones; scrophulae, los lamparones, enfermedad que parece en el cuello; stetokirti, el lamparón, struma gibbuf; sturinae, scrophulae, el lamparón, o carne seca que no se puede deshazer; struma, lo mismo, y el humor virulento que purgan las mugeres de la madre; v. estruma. scrophula, v. lamparón. 
scrophulae, v. lamparón.

scrophularia, yerua que cura lamparones.

Oudin 1607 [= Oudin, César (1607): Tesoro de las dos lenguas francesa y española. Thresor des deux langues françoise et espagnolle, París, Marc Orry]

lamparones, escrouelles, c'est vne sorte de maladie que les roys de France guarissent en touchant le malade.

puerca, Escroüelle.

Vittori 1609 [= VITTORI, Girolamo (1609): Tesoro de las tres lengvas francesa, italiana y española Thresor des trois langues françoise, italienne et espagnolle, Ginebra, Philipe Albert \& Alexandre Pernet]

lamparones, escrouelles, maladie, le scrofole o scroue, malatia.

puerca, escrouelle.

scrofola, scroua, malatia.

Covarrubias 1611 [= COVARRUBIAS, Sebastián de (1611): Tesoro de la lengua castellana o española, Madrid, Luis Sánchez]

lamparon, enfermedad conocida que nace en la garganta. Danle diuersos nombres, struma, cheras, scrofula, est tumor in quo quasi glandulae durae, oriuntur in ceruice et alis, membrana sua inclusae. Esta enfermedad es ordinaria en los puercos, y assi tomò el nombre dellos, y en castellano se pudo decir lamparon [...], splendor, porque la cutis del lamparon tiene vn cierto resplandor albicante, por estar tan estirado y por su corrosion. Los Reyes de Francia dizen tener gracia de curar los lamparones, y el primer Rey Ingles que fue Edouardo tuuo la misma gracia, y de algunos otros particulares tambien se ha dicho.

G. López 1612 [= LÓPEZ, Gregorio (1612): Tesoro de medicinas para todas enfermedades, edición de Francisco Guerra, Madrid, Ediciones Cultura Hispánica, 1982]

lamparones, es hinchazón dura de las landreçillas y otras partes embuelta en una tela. O las mismas landrezillas combertidas em scirros, son strumas o lamparones, házense de rumores gruesos y flemáticos [...].

struma, v. lamparón.

Soler 1615 [= SOLER, Bernabé (1615): Thesavrus pverilis, Valencia, Pedro Patricio Mey] lamparones, cherades, strumae, parotidae; el que tiene tal enfermedad; strumosus, a, um.

Minsheu 1617 [= MinsHeU, John (1617): Vocabularium Hispanicum Latinum et Anglicum copiossisimum, cum nonnullis vocum millibus locupletatum, ac cum Linguae Hispanica Etymologijs, Londres, Joanum Browne]

lamparón, lat. struma, scrofula; angl. a wenne, or a swelling in the necke, also the kings evill; [...]. puercas, $v t$ lamparones.

Franciosini 1620 [= Franciosini Florentín, Lorenzo (1620): Vocabulario español-italiano, ahora nuevamente sacado a luz [...]. Segunda parte, Roma, Iuan Pablo Profilio]

lamparón, scrofe, male che viene alla gola, e che dicono che i Rè di Francia hanno grazia particolare per sanarle.

Noviliers 1629 [= NoviliERs Clavel, Guillermo Alejandro (1629): Nomenclatvra italiana, francesa y española con los términos propios de cada capitulo [...], Venecia, Barezzo Barezzi]

le scròfole; les escrouëlles, los lamparones, las landrezillas.

Pereira 1634 [= PEREIRA, Bento (1634): Prosodia in vocabvlarivm trilingve latinvm, lvsitanicvm et hispanicum digesta [...], Évora, Emmanuel Carvalho] struma, ae, a alporca, lamparón [...]

Seguin 1636 [= SEguIn, Pierre (1636): Dictionario español, manuscrito esp. 298 de la Bibliothèque Nationale de France, París] lamparón, escrouelle; lamparones, escrouelles. 
puercas, glandes, escrouelles.

puerca o lamparón, escrouelle.

puercas con lamparones, pourceau qui a les glandes.

serofularia [scrofularia] menor, herbe aux esrouelles.

Trognesius 1639 [= ANÓNIMO (1639): El grande dictionario y thesoro de las tres lenguas Española,

Francesa y Flamenca, con todos los nombres de los Reynos, Ciudades y lugares del Mundo, Amberes, César Joaquín Trognesius]

lamparones, escrouelles, c'est vne sorte de maladie que les roys de France guarissent en touchant le malade; conincks-seer.

Salas 1645 [= SALAS, Pedro de (1645): Thesavrus hispanolatinvs vtrivsque lingvae dives opvm, Valladolid, Gregorio de Bedoya]

lamparón, struma, ae, cherades, um, strofulae, arum.

[puerca] parida, scropha, ae.

Oudin 1647 [= OudIN, Antoine (1647): Nomenclatvre francois et espagnol, París, Antoine de Sommaville] escroüelles, lamparones.

Julliani 1659 [= Julliani, Sieur (1659): Nomenclatvre dv sievr Ivlliani, qui contient les mots exacts et choisis pour apprendre les langues fraçoises, italiennes, et espagnoles [...], París, Jean Baptiste Loyson]

le scrôffole; les escrouëlles; lamparones.

Huillery 1661 [= HUILLERY, Francisco (1661): Vocabvlario para más fácilmente y brieuemente deprender a leer, escrebir y hablar la lengua castellana, París, Pierre Variquet]

lamparones es vn mal y enfermedad pegajosa, y se gana bebiendo, comiendo o acostándose con el que tiene esse mal, el qual los médicos ny serujanos [cirujanos] no pueden curar ny sanar [...], escrouëlle est vn mal cruel qui se prend en couchant, beuuant et mangeant auec ceux qui'en sont attaints, et dont les chirurgiens et medecins n'ont pas encore pû découurir l'origine; aussi n'ya-t'il pas vn seul Operateur qui en puisse acheuer la guerison. [...]

Henríquez 1679 [= HENRíQUEZ, Baltasar (1679): Thesaurus utriusque linguae hispanae et latinae, Matriti, Ioannis Garcia Infançon]

lamparón, struma, ae [...].

[puerca] para criar, scrofa, ae.

Perger 1704 [= PERGER, Monsieur (1704): Nouvelle grammaire de la langue espagnolle contenant les principes de cette langue, avec la nomenclature des mots les plus necessaires et plusieurs historiettes espagnoles et françoises, París, Pierre Ribou]

les écroüilles, los lamparones.

Sobrino 1705 [= SoBRINO, Francisco (1705): Diccionario nuevo de las lenguas española y francesa, Bruselas, Francisco Foppens]

lamparones, m. Ecrouelles, sorte de maladie que les Rois de France guerissent en touchant le malade.

lamparones de cavallos, le farcin du cheval.

Stevens 1706 [= STEvens, John (1706): A new Spanish and English Dictionary. Collected from the Best Spanish Authors Both Ancient and Modern, Londres, George Sawbrige]

lamparones, the distemper call'd the king's evil, also the farcy in a horse.

puercas, kernels growing in the throat, or other parts of the body.

Guilla 1707 [= GuILla RuBí, Abdón Senén (1707): Forma gramatical, la qval contiene el modo como se ha de aprender a leer y hablar la lengua francesa, Madrid, Imprenta de Agustín Fernández] lamparones, ecroüelles.

Kramer 1711 [= KRAMER, Matthias (1711): Grammaticae Hispanicae seu castellanae [...], t. III, s. i., s. 1., s. a. [Johannes Ziegerm, Nüremberg]] 
lamparones, landrecillas, puerca, ecroüelles.

puerca.v. lamparón.

Bluteau 1721 [= BLUTEAU, Raphael (1721): Diccionario castellano y portuguez para facilitar a los curiosos la noticia de la lengua latina, con el vso del vocabulario portuguez y latino [...], Lisboa, Pascoal da Sylva]

lamparones, alporcas.

puerca. Alporca.

Andree 1725 [= ANDREE, John (1725): A vocabulary in six languages, Londres, P. Vaillat]

ingl. King's evil; lat. struma, ital., scrofole; fr. ecrouëlles; esp. lamparones, landrezillas; port. alporcas.

Academia Autoridades (G-M) 1734 [= ReAl ACADEMIa Española (1734): Diccionario de la lengua castellana, en que se explica el verdadero sentido de las voces, su naturaleza y calidad, (...). Tomo quarto. Que contiene las letras G.H.I.J.K.L.M.N, Madrid, Imprenta de la Real Academia Española, por los herederos de Francisco del Hierro]

Lamparon. s. m. Tumór duro, que se hace en las glandulas conglomeradas del cuello, ù de las que llaman Salibales, por la crassitud de la lympha ù de otros cuerpos, por un acido alli estancado, el qual obstruye los túbulos de las referidas glándulas. Covarr. dice se pudo llamar Lamparón, por la especie de resplandór blanquecino que tiene el cutis de los lamparónes, a cáusa de lo estirado que está con su misma inflamacion. Lat. Struma. Scrophula. [...]

Academia Autoridades (O-R) 1737 [= ReAl ACAdEmia Española (1737): Diccionario de la lengua castellana, en que se explica el verdadero sentido de las voces, su naturaleza y calidad, (...). Tomo quinto. Que contiene las letras O.P.Q.R., Madrid, Imprenta de la Real Academia Española, por los herederos de Francisco del Hierro]

Puercas. Se llaman tambien cierta especie de tumóres à modo de lamparónes. Trahenlo en este sentido Nebrixa y el P. Alcalá en sus Vocabularios. Lat. Scrophulae. Strumata.

Academia Usual 1780 [= ReAl ACADEMIA EsPañola (1780): Diccionario de la lengua castellana compuesto por la Real Academia Española, reducido a un tomo para su más fácil uso, Madrid, Joachín Ibarra]

Lamparon. s. m. Tumor duro, que se hace en las glándulas conglomeradas del cuello, ó de las que llaman salivales, por la crasitud de la linfa, ó de otros cuerpos, por un ácido allí estancado, el qual obstruye los túbulos de las referidas glándulas. Struma, scrophula.

Puercas. p. Cierta especie de tumores á modo de lamparones. Scrophulae, strumata.

Academia Usual 1783 [= REAL ACADEMIA EsPaÑola (1783): Diccionario de la lengua castellana compuesto por la Real Academia Española, reducido a un tomo para su más fácil uso. Segunda edición, en la qual se han colocado en los lugares correspondientes todas las voces del Suplemento, que se puso al fin de la edición del año 1780, y se ha añadido otro nuevo suplemento de artículos correspondientes a las letras $A$, $B$ y $C$, Madrid, Joachín Ibarra]

Escrófula. s. f. La glándula, ó landrecilla dura, que se hace en el cuello, ó ingles, particularmente se dice del lamparon.

Escrofuloso, sa. adj. Lo perteneciente á la escrófula, ó el que las padece.

Terreros y Pando 1787 [= TERREROS Y PANDO, Esteban de (1787): Diccionario castellano con las voces de ciencias y artes y sus correspondientes en las tres lenguas francesa, latina e italiana [...]. Tomo segundo, Madrid, Viuda de Ibarra]

Lamparón, pl. lamparónes, tumores escirrosos, que salen en el cuello, ó garganta. Fr. Ecrouelles, scrofule. Lat. Strumae, scróphula. It. Scrofe, scrofole.

El que tiene lamparones. Fr. Ecrouellé. Lat. Strumárum morbo labórans, strumósus. It. Che patisce di scrofole. 
Terreros y Pando 1788 [= TERREROS Y PANDO, Esteban de (1788): Diccionario castellano con las voces de ciencias y artes y sus correspondientes en las tres lenguas francesa, latina e italiana [...], Tomo tercero, Madrid, Viuda de Ibarra]

Escrófula, termino de Medicina, lo mismo que landre, ó vulto, que se hace en la garganta, sobaco, \&c. Fr. Glande. Lat. Glándula, scróphulae; aunque esto propiamente se toma por el vulto de la garganta, [...].

Escrofularia, planta, que sirve para limpiar las materias de las heridas; y para resolver los tumores, y lamparones, llamados en Latin Scrophulae, de donde se tomó el nombre Cast. y Fr. Scrofulaire. Lat. Scrophulária nodósa, foétida.

Escrofulóso, adj. lo que toca á escrófula. Fr. Scrofuleux, scrophuleux. Lat. Ad scróphulas pértinens.

Puerca, segun algunos, especie de Lamparon. V.

Academia Usual 1791 [= REAl ACADEMIA ESPAÑola (1791): Diccionario de la lengua castellana compuesto por la Real Academia Española, reducido a un tomo para su más fácil uso. Tercera edición, en la qual se han colocado en los lugares correspondientes todas las voces de los suplementos, que se pusieron al fin de las ediciones de los año 1780 y 1783, y se han intercalado en las letras D. E y F nuevos artículos, de los quales se dará un sumplemento separado, Madrid, Viuda de Joaquín Ibarra]

Escrófula. s. f. Med. Lo mismo que lamparon.

Escrofuloso, sa. adj. Lo perteneciente á la escrófula, ó el que la padece. Ad scrofulam pertinens, vel scrofulis laborans.

Academia Usual 1803 [= ReAl ACADEMIA EsPañola (1803): Diccionario de la lengua castellana compuesto por la Real Academia Española, reducido a un tomo para su más fácil uso. Quarta edición, Madrid, Viuda de Ibarra]

Lamparon. s. m. Tumor duro que se forma por obstruirse las glándulas del cuello. Scrofulae.

Núñez de Taboada 1825 [= NúÑEZ DE TABOADA, Manuel (1825): Diccionario de la lengua castellana, para cuya composición se han consultado los mejores vocabularios de esta lengua y el de la Real Academia Española, últimamente publicado en 1822; aumentado con más de 5000 voces o artículos que no se hallan en ninguno de ellos, Paris, Seguin, 2 vols.]

Escrófula, s. f. Med. V. lamparon.

Escrofuloso, sa, adj. Perteneciente á la escrófula, ó que la padece.

Lamparon, s. m. Tumor duro que se forma á efecto de obstruirse las glándulas del cuello.

Puerca. Cierta especie de tumor á modo de lamparon.

Salvá 1846 [= SALVÁ, Vicente (1846): Nuevo diccionario de la lengua castellana, que comprende la última edición integra, muy rectificada y mejorada del publicado por la Academia Española, y unas veinte y seis mil voces, acepciones, frases y locuciones, entre ellas muchas americanas [...], París, Vicente Salvá]

Escrófula. f. Med. Lamparon. Scrofulae.

Escrofularia. f. Yerba. Celidonia menor.

Escrofuloso, sa. adj. Lo perteneciente á la escrófula, ó el que la padece. Ad scrofulas pertinens, vel a scrofulis laborans.

Lamparon. m. Tumor que se forma en las glándulas del cuello. [Es mas usado en plural.] Scrofulae.

Puerca. Cierta especie de tumor á modo de lamparon. Struma.

Domínguez 1853 [= DomínguEz, Ramón Joaquín (1853): Diccionario Nacional o Gran Diccionario Clásico de la Lengua Española (1846-47), Madrid-París, Establecimiento de Mellado, 2 vols., $5^{\text {a }}$ ed.]

Escrófulas, s. f. pl. Med. Enfermedad que consiste en una degeneracion de los ganglios linfáticos superficiales, y particularmente los del cuello, con alteracion de los fluidos que los atraviesan. Se manifiesta esta enfermedad por unos tumores irregulares, duros y móviles que ocupan las glándulas ó ganglios linfáticos del cuello, de la axila etc. sin alteracion de color en la piel.

Escrofularia, s. f. Bot. Planta de la familia de las persóneas, [...], muy recomendada antiguamente como remedio contra las escrófulas. 
Escrofuloso, sa. adj. Concerniente a las escrófulas, propio de ellas, ó que participa de su naturaleza. || Que padece de escrófulas. Se usa como sustantivo.

Estruma, Patol. V. Escrófula.

Estrumífero, ra, adj. Que tiene estrumas. \| Zool. Que tiene papera, tumefacción ó cosa parecida.

Estrumosidad, s. f. Patol. Reunion, acumulacion ó aglomeramiento de tumores en diferentes partes del cuerpo, que suele operar en las organizaciones predispuestas á las escrófulas.

Estrumoso, sa. V. Escrofuloso, sa.

Lamparon. V. Escrófulas. Úsase generalmente en plural.

Puerca. Cierta especie de tumor á modo de lamparon.

Gaspar y Roig (A-F) 1853 [= BiBlioteCA IlustradA DE GASPAR Y ROIG (1853): Diccionario enciclopédico de la lengua española, con todas las vozes, frases, refranes y locuciones usadas en España y las Américas Españolas [...], Tomo I, Madrid, Imprenta y Librería de Gaspar y Roig]

Escrófula. s. f. Med.: enfermedad caracterizada por una dejeneracion de los gánglios linfáticos superficiales, y particularmente de los del cuello, con alteracion de los fluidos que los atraviesan. Manifiéstase por la aparicion de unos tumores irregulares, duros, indololentes, movibles, que ocupan las glándulas o gánglios linfáticos del cuello, de la axila, etc., sin alteracion en el color de la piel. Las escrófulas son conocidas vulgarmente con el nombre de lamparones y tumores fríos.

Escrofularia. s. f. Bot.: género de plantas de la familia de las escrofularíneas [...]; el nombre de escrofularia se le dió por haber sido mirada durante mucho tiempo como remedio eficaz para curar las escrófulas. [...].

Escrofuloso. adj. Med.: lo perteneciente a la escrófula, o el que la padece.

Estruma: s. m. Med.: sinón. de escrófula, segun algunos autores, y segun otros, tumor de la glándula tiroidea, que puede presentarse en todas edades y que nunca llega a supurar.

Estrumosidad: s. f. Med.: grupo o reunion de muchos tumores en diversos puntos del cuerpo, y particularmente en el cuello de las personas que tienen una constitución escrofulosa o que suelen padecer escrófulas.

Estrumoso: adj. Med. Escrofuloso.

Gaspar y Roig (G-Z) 1855 [= BIBLIOTECA ILUSTRADA DE GASPAR Y ROIG (1855): Diccionario enciclopédico de la lengua española, con todas las vozes, frases, refranes y locuciones usadas en España y las Américas Españolas [...], Madrid, Imprenta y Librería de Gaspar y Roig]

Lamparon. Tumor que se forma en las glándulas del cuello.

Puerca. s. f. Cierta especie de tumor a modo de lamparon.

Academia Usual 1884 [= REAl ACADEMIA ESPAÑola (1844): Diccionario de la lengua castellana por la Real Academia Española. Duodécima edición, Madrid, Imprenta de D. Gregorio Hernando]

Escrófula. (Del lat. scrōfǔlae.) f. Med. Tumor frío originado de la hinchazón, con tubérculos ó sin ellos, de los ganglios linfáticos superficiales.

Lamparón. [...] Med. Escrófula en el cuello. \| Veter. Enfermedad de los solípedos, acompañada de erupción de tumores linfáticos en varios sitios.

Zerolo 1895 [= ZEROLO, Elías (1895): Diccionario enciclopédico de la lengua castellana, París, Garnier hermanos]

*Escrófula. [Del lat. scrōfǔlae.] f. Med. Tumor frío originado de la hinchazón, con tubérculos ó sin ellos, de los ganglios linfáticos superficiales.

*Escrofuloso, sa. adj. 1. Med. Perteneciente á la escrófula 2. adj. y s. Med. Que la padece.

Estruma. f. Med. Escrófulas.

Estrumosidad. f. Med. Conjunto de muchos tumores que se presentan generalmente en el cuello en los escrofulosos.

Lamparón. [...] 3. Med. Escrófula en el cuello. 4. Veter. Enfermedad de los solípedos acompañada de erupción de tumores linfáticos en varios sitios.

Puerca. Cierta especie de tumor á modo de lamparón. 
Academia Usual 1899 [= REAL ACADEMIA ESPAÑola (1899): Diccionario de la lengua castellana por la Real Academia Española. Décimotercia edición, Madrid, Imprenta de los Sres. Hernando y compañía] Escrófula. (Del lat. scrofúlae.) f. Med. Tumor frío originado de la hinchazón, con tubérculos ó sin ellos, de los ganglios linfáticos superficiales.

f. $[\ldots]$.

Escrofularia. (De escrófula, por haberse usado esta planta como medicamento para las paperas.)

Puerca. Escrófula.

Toro y Gómez 1901 [= TORO y GómEz, Miguel de (1901): Nuevo diccionario enciclopédico ilustrado de la lengua castellana, París-Madrid, Librería Armand Colin-Hernando y Cía.]

Escrófula, f. Med. Tumor frío originado de la hinchazón de los ganglios linfáticos. [...]

Escrofuloso, sa, adj. Perteneciente a la escrófula. \|| adj. y s. Que la padece.

Estruma, f. Med. Escrófula.

Estrumosidad, f. Med. Agrupación de tumores.

Estrumoso, sa, adj. Escrofuloso.

Lamparón. [...] Med. Escrófula en el cuello. \|Veter. Enfermedad linfática de los solípedos.

Puerca. Escrófula.

Pagés (C-E) 1904 [= PAGÉs, Aniceto de (1904): Gran diccionario de la lengua castellana (de Autoridades), con ejemplos de buenos escritores antiguos y modernos [...], Tomo segundo, Barcelona, Pedro Ortega] Escrófula (del lat. scrofúlae): f. Med. Tumor frío originado de la hinchazón, con tubérculos ó sin ellos, de los ganglios linfáticos superficiales. $[\ldots]$.

Escrofularia (de escrófula, por haberse usado esta planta como medicamento para las paperas.) f.

Escrofuloso, sa: adj. Med. Perteneciente á la escrófula. [...]\| Med. Que padece escrófula. [...]

Pagés (F-M) 1914 [= PAGÉS, Aniceto de (ca 1914): Gran diccionario de la lengua castellana (de Autoridades), con ejemplos de buenos escritores antiguos y modernos [...], Tomo tercero, Barcelona, Fomento comercial del libro]

Lamparón. [...] Med. Escrófula en el cuello [...].|| Veter. Enfermedad linfática de los solípedos, acompañada de erupción de tumores linfáticos en varios sitios.

Alemany y Bolufer 1917 [= Alemany y Bolufer, José (1917): Diccionario de la Lengua Española, Barcelona, Ramón Sopena]

Escrófula. (del lat. scrofǔlae, paperas). f. Pat. Tumor frío originado de la hinchazón de los ganglios linfáticos superficiales. $[\ldots]$.

Escrofularia. (de escrófula, por haberse usado esta planta como medicamento para las paperas)

Escrofúlide. (de escrófula y el gr. eidos, forma, aspecto). f. Pat. Nombre de toda afección de la piel o de las mucosas, que se desenvuelve bajo la influencia de la escrófula.

Escrofulismo. m. Escrofulosis.

Escrofulosis, f. Pat. Conjunto de afecciones a las que la escrófula imprime un sello especial.

Escrofuloso, sa. adj. Pat. Perteneciente a la escrófula. \| Pat. Que la padece. [...]

Estruma. (del lat. strūma, papera). f. Pat. Escrófula.

Estrumitis. (del lat. strūma, papera, y el suf. itis que indica flegmasía). f. Pat. Inflamación del cuerpo tiroides, ya hipertrofiado.

Estrumosidad. (de estrumoso), f. Pat. Agrupación de tumores.

Estrumoso, sa (de estruma), adj. Escrofuloso.

Lamparón. [...] Med. Escrófula en el cuello [...].|| Veter. Enfermedad linfática de los solípedos, acompañada de erupción de tumores linfáticos en varios sitios.

Puerca. Escrófula.

Rodríguez Navas 1918 [= RODRíGUEz NAVAS y CARRASCO, Manuel (1918): Diccionario general y técnico hispano-americano, Madrid, Cultura Hispanoamericana] 